\title{
Implementation of Polar WRF for short range prediction of weather over Maitri region in Antarctica
}

\author{
Anupam Kumar ${ }^{1,2}$, S K Roy Bhowmik ${ }^{1, *}$ and AnAnda K Das ${ }^{1}$ \\ ${ }^{1}$ India Meteorological Department, New Delhi 110 003, India. \\ ${ }^{2}$ Present affiliation: Asia Risk Centre (an affiliate of RMS), Noida, U.P., India. \\ ${ }^{*}$ Corresponding author.e-mail: skrb@imdmail.gov.in_skrb.imd@gmail.com
}

India Meteorological Department has implemented Polar WRF model for the Maitri (lat. $70^{\circ} 45^{\prime} \mathrm{S}$, long. $11^{\circ} 44^{\prime} \mathrm{E}$ ) region at the horizontal resolution of $15 \mathrm{~km}$ using initial and boundary conditions of the Global Forecast System (GFS T-382) operational at the India Meteorological Department (IMD). Main objective of this paper is to examine the performance skill of the model in the short-range time scale over the Maitri region. An inter-comparison of the time series of daily mean sea level pressure and surface winds of Maitri for the 24 hours and 48 hours forecast against the corresponding observed fields has been made using 90 days data for the period from 1 December 2010 to 28 February 2011. The result reveals that the performance of the Polar WRF is reasonable, good and superior to that of IMD GFS forecasts. GFS shows an underestimation of mean sea level pressure of the order of 16-17 hPa with root mean square errors (RMSE) of order $21 \mathrm{hPa}$, whereas Polar WRF shows an overestimation of the order of 3-4 hPa with RMSE of $4 \mathrm{hPa}$. For the surface wind, GFS shows an overestimation of 1.9 knots at 24 hours forecast and an underestimation of 3.7 knots at 48 hours forecast with RMSE ranging between 8 and 11 knots. Whereas Polar WRF shows underestimation of 1.4 knots and 1.2 knots at 24 hours and 48 hours forecast with RMSE of 5 knots. The results of a case study illustrated in this paper, reveal that the model is capable of capturing synoptic weather features of Antarctic region. The performance of the model is found to be comparable with that of Antarctic Meso-scale Prediction System (AMPS) products.

\section{Introduction}

The Indian Antarctic program is a multidisciplinary and multi-institutional program under the control of the National Centre for Antarctic and Ocean Research. It was initiated in 1981 with the first Indian expedition to Antarctica. Under the program (Pandey 2007), atmospheric, biological, earth, chemical and medical sciences are being studied by India. The first permanent settlement was built in 1983 at Dakshin Gangotri (lat. $70^{\circ} 45^{\prime} \mathrm{S}$, long. $12^{\circ} 30^{\prime} \mathrm{E}$ ). In 1989 it was abandoned after it got buried in ice and Maitri base (lat. $70^{\circ} 45^{\prime} \mathrm{S}$, long. $11^{\circ} 44^{\prime} \mathrm{E}$ ) was constructed in 1990. Recently, India has constructed another new base called 'Lawrence Hills', located at lat. $69^{\circ} 24^{\prime} \mathrm{S}$, long. $76^{\circ} 11^{\prime} \mathrm{E}$. The new base is now named as 'Bharati'.

Antarctica (Schwedtfeger 1984) is the coldest, windiest, highest, driest, and iciest continent on Earth. The general circulation pattern has the winds moving coastward from the polar plateau, turning left under the effect of the Coriolis force and merging with the coastal polar easterlies. Katabatic flow of Antarctica region is well known for producing extremely strong sustained winds.

Keywords. Numerical weather prediction; Polar WRF; polar meteorology. 
Blizzards are a typical Antarctic phenomenon occurring when drift snow is picked up and blown along the surface by the violent winds. A severe blizzard may last for a week at a time with winds blasting at over 100 miles/hour. One of the most remarkable features of the sub-Antarctic latitudes is the high frequency of cyclonic storms, many of which are intense. These systems have a large impact on weather in the region and particularly at coastal locations, where most Antarctic stations are located. Mesocyclones are relatively shortlived, sub-synoptic-scale low-pressure systems that occur in both polar regions. They generally exist for less than 24 hours and have a horizontal extent up to $1000 \mathrm{~km}$.

Logistic and scientific operations in Antarctica are critically dependent on the accurate weather forecasts. Presently daily forecasts for Maitri are produced based on available observations, satellite pictures and the synoptic charts provided by Weather Service of South Africa. The safety of personnel and economic operations in Antarctica depend on the accuracy of these forecasts.

For the operation of real time mesoscale NWP modelling over Antarctica, the challenges include poor first guess and boundary conditions, shortage of conventional meteorological observations and the polar atmosphere itself. Antarctica lacks the dense data network needed to provide mesoscale NWP model with an accurate representation of the large scale circulation. For skillful forecasts the model must accurately represent the Antarctic katabatic winds that are governed by the balance of gravity, thermal stability and synoptic forcing (elevated ice sheet), sea ice that impacts the atmosphere ocean interactions (Cassano and Parish 2000; Cassano et al. 2001a; Parish and Cassano 2003; Pavolonis et al. 2004). A polar-optimized version of the state-of-the-art Weather Research and Forecasting model (WRF) was developed for the Greenland region by the Polar Meteorology Group of Ohio State University's Byrd Polar Research Center (Powers 2007; Hines and Bromwich 2008).

Recently, a version of the Polar WRF adapted from Polar Meteorology Group is configured for the Maitri region with the use of initial and boundary conditions of Global Forecast System (GFS) operational at India Meteorological Department (IMD). After necessary testing and validation, the model is made operational and products are made available in the real-time mode in the IMD website: www.imd.gov.in. Performance skill of the model is presented in this paper.

A brief description of Polar WRF is given in section 2. The design of model set-up and model configurations are described in section 3. Results of performance skill are discussed in section 4 and finally concluding remarks are given in section 5 .

\section{The development of Polar WRF}

Antarctic Meso-scale Prediction System (AMPS) was providing real-time mesoscale NWP products for the Antarctic region since September 2000 (Powers et al. 2003). This system was built around the Polar Meso-scale Model (Polar MM5), a version of the fifth generation Pennsylvania State University National Centre for Atmospheric Research Meso-scale model, which was adapted at the Byrd Polar Research Centre at the Ohio State University (Bromwich et al. 2001; Cassano et al. 2001b). Polar MM5 was used until June 2008 to make the forecasts, but is currently using the new mesoscale model - Polar WRF. To continue the goal of enhanced polar mesoscale modelling, polar optimization was applied towards the state-ofthe-art Weather Research and Forecasting (WRF) model (Powers 2007; Hines and Bromwich 2008). The key modifications made for the Polar WRF are:

- Optimal surface energy balance and heat transfer for the Noah Land Surface Model (LSM) over sea ice and permanent ice surfaces,

- Implementation of a variable sea ice thickness and snow thickness over sea ice for the Noah LSM, and

- Implementation of seasonally-varying sea ice albedo in the Noah LSM.

The Polar WRF has been continuously becoming very sophisticated with new changes every year (PWRF2.0, 2.2, 3.0, 3.0.1.1, 3.2). The Polar WRF version 3.1.1, with fractional sea ice as a standard option was released by Polar Meteorology Group on 5 October 2009. The important new features include the possibility of variable specified sea ice thickness and variable specified snow depth on sea ice. The fractional sea ice description as well as the modification of NOAH LSM is required for sea ice sheets (Hines and Bromwich 2008). The polar-optimizations are performed for the boundary layer parameterization, cloud physics, snow surface physics and sea ice treatment. The testing and development work for Polar WRF began with both winter and summer simulations for ice sheet surface conditions using Greenland area domains (Hines and Bromwich 2008). The polar modifications in V3.1.1 address sea ice and the Noah LSM, which are summarized as follows:

- Sea ice: Capability to handle fractional coverage in grid cells

- Noah LSM modifications: Use of the latent heat of sublimation for calculations of latent heat fluxes over ice/snow surfaces 
- Adjustment of snow density, heat capacity, thermal diffusivity, and albedo (increase to 0.80 ) over ice points

- Use of snow thermal diffusivity if snow coverage $>97 \%$

- Sea/land ice points soil moisture $=1.0$

- Albedo and emissivity of sea ice set to 0.80 and 0.98

- Thermal conductivity on sea/land ice set to snow thermal conductivity

- Call to soil moisture flux subroutine skipped for sea/land ice points

- Limit on depth of snow layer in soil heat flux calculation

- No limit on snow cover fraction over sea/land ice

\section{Configuration of Polar WRF for Maitri region}

With the commissioning of High Performance Computing System (HPCS), National Centre for Environmental Prediction (NCEP) based Global Forecast System (GFS T-382) was made operational at IMD New Delhi, incorporating Global Statistical Interpolation (GSI) scheme as the global data assimilation for the forecast up to 7 days.
The performance skill of the model in the medium range time scale to predict rainfall and other characteristic features of Indian summer monsoon in temporal and spatial scale during summer monsoon 2010 is documented by Roy Bhowmik and Durai (2010). The verification results show that the IMD GFS forecasts have reasonably good capability to capture characteristic features of summer monsoon such as, lower tropospheric strong cross equatorial flow, monsoon trough at $850 \mathrm{hPa}$ and position of ridge at the $200 \mathrm{hPa}$. Large scale rainfall features of summer monsoon, such as heavy rainfall belt along the west coast, over the domain of monsoon trough and along the foothills of the Himalayas are predicted well. Spatial correlation of coefficient (CC) of rainfall between the observed grid point value and corresponding forecast grid point value over the Indian land area ranges between 0.33 and 0.22 for the forecasts up to 5 days. The corresponding skill score (spatial CC) for the NCEP GFS is between 0.28 and 0.20 . Ingesting of more local observations in the assimilation cycle of the model resulted better initial condition of the model and thereby provided better performance of IMD GFS over the Indian region. The root mean square of the forecasts for the upper air parameters for the monsoon months for the domain of entire globe and southern hemisphere is

Table 1. RMSE of forecasts of upper air parameters for the period from 1 June to 30 September 2010 of IMD GFS T 382.

\begin{tabular}{|c|c|c|c|c|c|c|c|}
\hline \multirow[b]{2}{*}{ GFS } & \multirow{2}{*}{$\begin{array}{l}\text { Level } \\
\text { (hpa) }\end{array}$} & \multicolumn{3}{|c|}{ Globe } & \multicolumn{3}{|c|}{ Southern Hemisphere } \\
\hline & & $\mathrm{U}$ & $\mathrm{V}$ & $\mathrm{H}$ & $\mathrm{U}$ & $\mathrm{V}$ & $\mathrm{H}$ \\
\hline \multirow[t]{3}{*}{ Day 1} & 850 & 2.09 & 2.06 & 8.25 & 2.52 & 2.52 & 11.12 \\
\hline & 500 & 2.58 & 2.59 & 9.38 & 3.28 & 3.32 & 12.92 \\
\hline & 200 & 3.54 & 3.54 & 11.85 & 3.32 & 3.34 & 14.19 \\
\hline \multirow[t]{3}{*}{ Day 2} & 850 & 3.08 & 3.02 & 13.91 & 3.78 & 3.78 & 19.48 \\
\hline & 500 & 3.86 & 3.88 & 17.10 & 4.91 & 5.05 & 24.13 \\
\hline & 200 & 5.07 & 5.10 & 21.09 & 4.90 & 4.99 & 26.03 \\
\hline \multirow[t]{3}{*}{ Day 3} & 850 & 3.87 & 3.80 & 20.51 & 4.87 & 4.90 & 29.44 \\
\hline & 500 & 4.91 & 5.00 & 26.31 & 6.34 & 6.66 & 37.82 \\
\hline & 200 & 6.35 & 6.44 & 32.31 & 6.49 & 6.71 & 41.60 \\
\hline \multirow[t]{3}{*}{ Day 4} & 850 & 4.59 & 4.56 & 27.93 & 5.89 & 6.04 & 40.57 \\
\hline & 500 & 5.90 & 6.11 & 36.84 & 7.68 & 8.28 & 53.31 \\
\hline & 200 & 7.62 & 7.82 & 45.41 & 8.14 & 8.56 & 60.09 \\
\hline \multirow[t]{3}{*}{ Day 5} & 850 & 5.27 & 5.27 & 35.86 & 6.88 & 7.11 & 52.36 \\
\hline & 500 & 6.86 & 7.16 & 48.15 & 8.99 & 9.80 & 69.69 \\
\hline & 200 & 8.97 & 9.25 & 60.28 & 9.94 & 10.60 & 80.95 \\
\hline \multirow[t]{3}{*}{ Day 6} & 850 & 5.86 & 5.92 & 43.61 & 7.68 & 8.07 & 63.49 \\
\hline & 500 & 7.72 & 8.10 & 59.37 & 10.16 & 11.16 & 85.66 \\
\hline & 200 & 10.22 & 10.65 & 75.39 & 11.67 & 12.64 & 102.19 \\
\hline \multirow[t]{3}{*}{ Day 7} & 850 & 6.39 & 6.42 & 50.74 & 8.42 & 8.80 & 73.91 \\
\hline & 500 & 8.54 & 8.96 & 70.27 & 11.27 & 12.41 & 101.52 \\
\hline & 200 & 11.47 & 12.02 & 90.49 & 13.40 & 14.67 & 123.78 \\
\hline
\end{tabular}

Note: $\mathrm{U}$ - zonal component of wind in knots, $\mathrm{V}$ - meridional component of wind and $\mathrm{H}$ - height in gpm. 


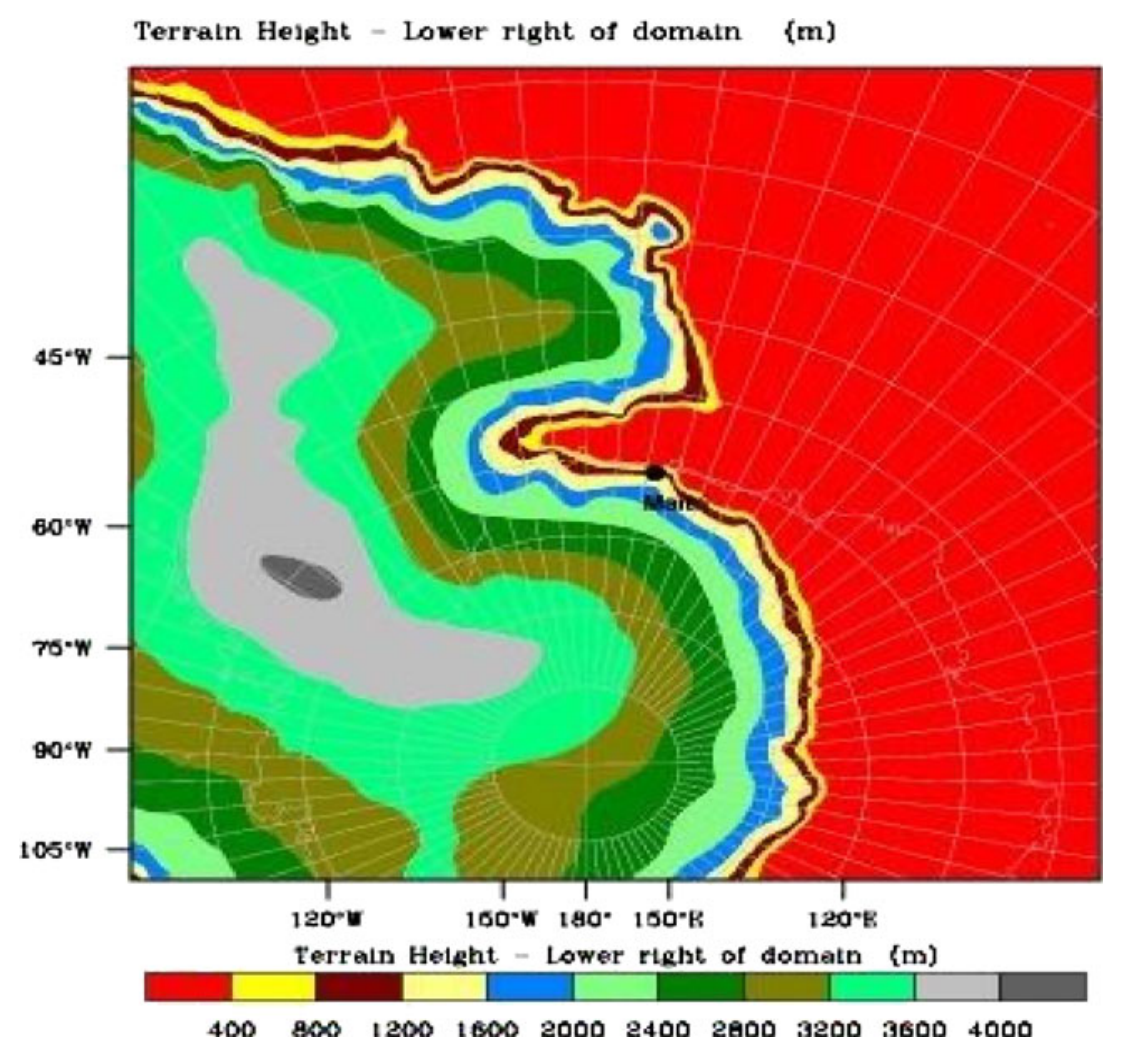

Figure 1. Model domain.

shown in table 1 . The performance results of the model are comparable with the global models of other leading centres.

Dynamical downscaling is a method for obtaining high-resolution weather information from relatively coarse-resolution global models. In an operational set-up, it is necessary to use the GFS outputs as the initial and boundary conditions in an indeginious way. Towards this direction, Polar WRF model (version 3.1.1) is configured for the forecast up to 48 hours over the Maitri region with the initial condition and 6 hourly boundary fields from GFS-T382 operational at IMD, New Delhi. A single static domain with $400 \times 400$ grids at 15 $\mathrm{km}$ horizontal spatial resolution and 39 vertical levels are used. Maitri (lat. $70^{\circ} 45^{\prime} \mathrm{S}$, long. $11^{\circ} 44^{\prime} \mathrm{E}$ ) is kept at the centre of the model domain. The model domain also includes other base station Bharati. The model domain is presented in figure 1 .

Physics options of the Polar WRF used in this work are: (a) Microphysics - WSM 5-class scheme, (b) Goddard short wave, (c) RRTM long wave, (d) Noah land-surface, (e) Planetary boundary layer - Mellor Yamada-Janjic, and (f) Cumulus convection - Grell-Devenyi. The modified code of the NOAA Land Surface Model (NOAA LSM), as appropriate for the Antarctica region is configured and incorporated in the WRF (ARW) version 3.1.1.

\section{Results of validation and discussion}

For quantitative assessment of performance of the model, daily observations of 0000 UTC recorded at the well-maintained observing site - Maitri for a period of 90 days starting from 1 December 2010 to 28 February 2011 are used. The performance statistics are computed for the location specific forecasts of 24 hours and 48 hours, generated interpolating outputs of Polar WRF. For the comparison purpose, the corresponding forecasts of IMD GFS T382 are used. In order to investigate the performance of Polar WRF to capture synoptic weather features of Antarctica region, case studies are also illustrated in this paper.

\subsection{Verification of daily location specific forecast fields}

The synoptic features of Antarctica are altogether different from those occur in the tropical regions. Antarctica is the coldest, windiest, highest, driest, and iciest continent on Earth. Its weather is characterized by extremes: extreme temperatures, extreme winds, and extremely variable localized conditions. Violent surface winds are experienced during the passage of intense land low pressure 

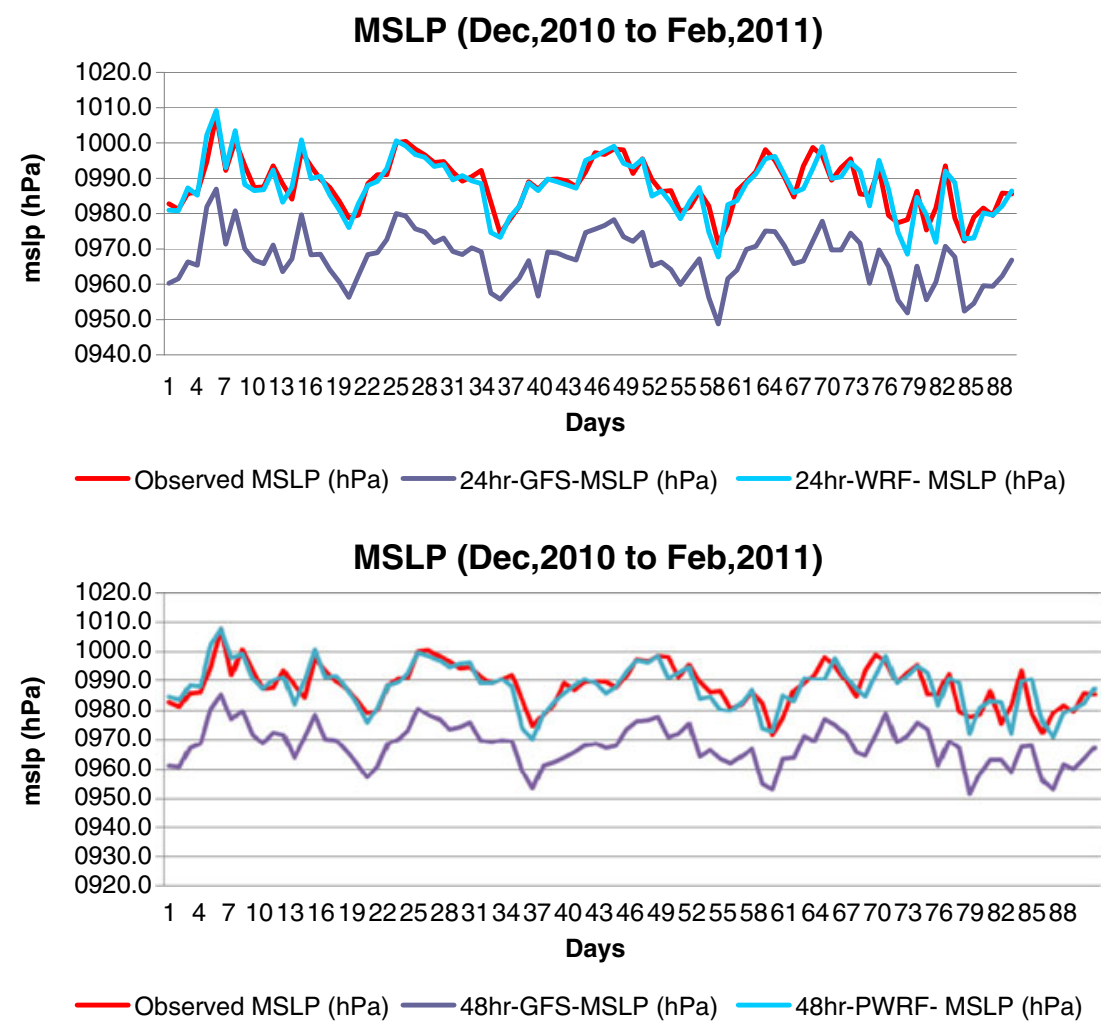

Figure 2. An inter-comparison of daily observed mean sea level pressure (hPa) of Maitri at 0000 UTC and corresponding 24 hours and 48 hours forecasts fields of Polar WRF and IMD GFS for the period from 1 December 2010 to 28 February 2011.

system. Thus mean sea level pressure and surface winds are two important parameters from the forecasting point of view.

Figure 2 shows an inter-comparison of daily observed mean sea level pressure $(\mathrm{hPa})$ of Maitri and corresponding 24 hours and 48 hours forecasts of mean sea level pressure from Polar WRF and IMD GFS for the period from 1 December 2010 to 28 February 2011. During this 90 days period the station experienced a number of frontal activities as reflected in the mean sea level pressure filed. The result shows that both Polar WRF and IMD GFS forecasts ( 24 hours as well as 48 hours) are able to capture daily ups and downs of mean sea level pressure filed. However, it is very encouraging to note that daily values of Polar WRF forecasts are close to the observed values, whereas IMD GFS shows a large systematic underestimation.

Mean errors (forecast-observed), RMSE and correlation coefficient between forecast and observed values of mean sea level pressure for 24 hours and 48 hours are presented in table 2. GFS shows an underestimation of mean sea level pressure of the order of 16 to $17 \mathrm{hPa}$, whereas Polar WRF shows

Table 2. 24 hours and 48 hours forecast skill scores of mean sea level pressure of Maitri for the period from 1 December 2010 to 28 February 2011.

\begin{tabular}{lcccc}
\hline & $\begin{array}{c}\text { Mean sea level } \\
\text { pressure }(\mathrm{hPa})\end{array}$ & $\begin{array}{c}\text { Mean errors } \\
(\mathrm{hPa})\end{array}$ & $\begin{array}{c}\text { Root mean square } \\
\text { errors }(\mathrm{hPa})\end{array}$ & $\begin{array}{c}\text { Correlation } \\
\text { coefficient }\end{array}$ \\
\hline $\mathbf{2 8}$ hours & & & & \\
$\quad$ Observation & 984.4 & & & \\
GFS & 967.3 & -17.1 & 21.3 & 0.91 \\
PWRF & 987.7 & 3.3 & 3.4 & 0.97 \\
$\mathbf{4 8}$ hours & & & & \\
Observation & 984.4 & -16.4 & 20.7 & 0.87 \\
GFS & 967.9 & 3.7 & 4.1 & 0.97 \\
PWRF & 988.1 & & & \\
\hline
\end{tabular}


an overestimation of the order of 3 to $4 \mathrm{hPa}$ for the forecast at 24 hours and 48 hours. RMSE of GFS forecasts ranges between 21.3 and $20.7 \mathrm{hPa}$, whereas for the Polar WRF it ranges between 3.4 and $4.1 \mathrm{hPa}$. Lower values of mean errors and root mean square errors of Polar WRF clearly indicate the superiority of Polar WRF forecasts over the GFS forecasts. The correlation coefficients against observations for the GFS forecast ranges between 0.91 and 0.87 and for the Polar WRF the value is 0.97 . The higher value of correlation coefficient indicates that both GFS and Polar WRF forecasts are able to capture daily trend of the observed mean sea level pressure. The result of mean sea level pressure shows that both GFS and Polar WRF have some systematic errors. The magnitude and character of these errors may vary from season to season (summer to winter). Thus there is a scope for removal of model's systematic biases from the use of longer model database by applying some statistical methods.

Global models are developed primarily for the tropics and mid-latitudes in the Northern Hemisphere and are not suitable for the Antarctica region. The higher magnitude of model errors in case of GFS may be partly due to inaccurate interpolation of model output at the station grid and partly due to wrong land surface process and model physics over the Antarctica region. The interpolation near the coastal escarpment is problematic, since the interpolation from grid points is done across high altitude, coastal sloping, and sea ice regions to the observation site. GFS is a spectral model (spectral harmonic basis functions) with transformation to Gaussian grid for calculation of nonlinear quantities and physics. Model outputs are prepared in Gaussian grid and vertically sigma-coordinate. Applying post-processing, model outputs are converted into regular grid and vertically pressure coordinate. The forecast parameters are then interpolated at Maitri station grid (lat. $70^{\circ} 45^{\prime} \mathrm{S}$, long. $11^{\circ} 44^{\prime} \mathrm{E}$ ) at an altitude of $130 \mathrm{~m}$, from the post-processed outputs. Whereas, WRF is a grid point model, where the dynamic solver integrates compressible, non-hydrostatic Euler equations. The equations in model are cast in flux form using variables that have conservation properties. The equations are formulated using a terrainfollowing mass vertical coordinate. In the WRF model forecast parameters are directly interpolated from the outputs in the Arakawa C-grid and vertically sigma-coordinate.

Figure 3 shows an inter-comparison of daily observed $10 \mathrm{~m}$ height wind speed of Maitri and

Wind (Dec,2010 to Feb,2011)

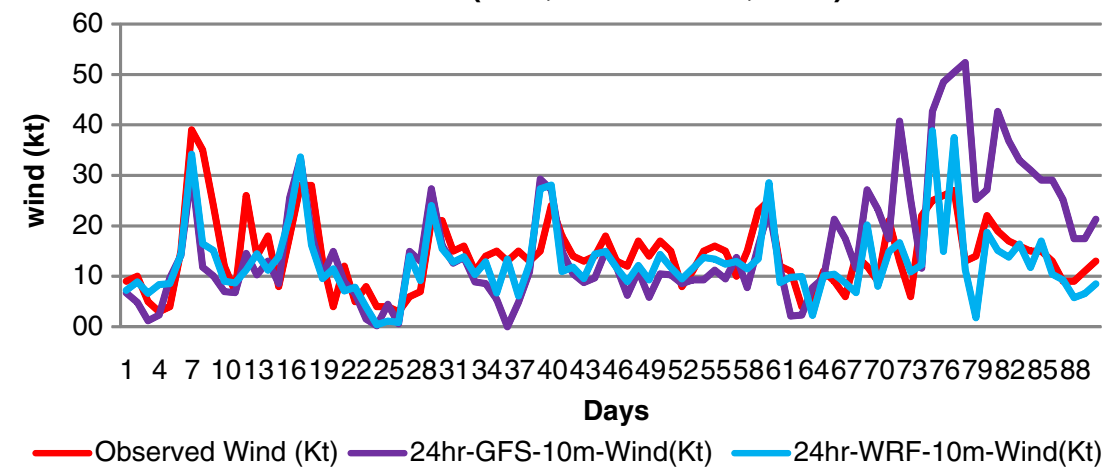

Wind (Dec,2010 to Feb,2011)

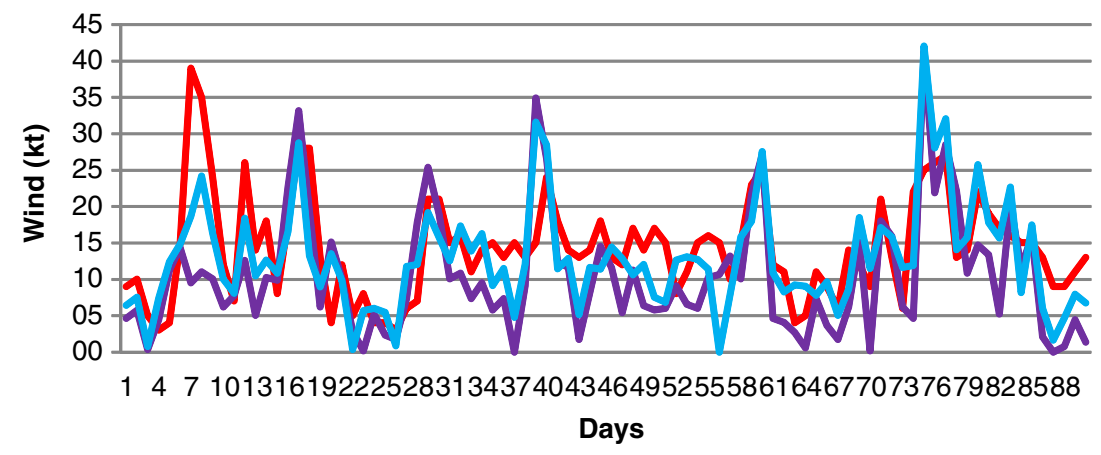

Observed Wind (Kt) $\longrightarrow$ 48hr-GFS-10m-Wind(Kt) $\longrightarrow 48 \mathrm{hr}-$ WRF-10m-Wind(Kt)

Figure 3. Same as figure 2, except for the $10 \mathrm{~m}$ height wind speed (knots). 
corresponding interpolated values of 24 hours and 48 hours forecasts of $10 \mathrm{~m}$ height wind speed from Polar WRF and IMD GFS for the period from 1 December 2010 to 28 February 2011, where strong katabatic winds are expected. In general, observed peak values are found to be well-matched with the corresponding forecast values.

Table 3 presents the performance skill of the models for $10 \mathrm{~m}$ height wind speed forecasts of Maitri station. GFS shows an overestimation of 1.9 knots at 24 hours forecast and an underestimation of 3.8 knots at 48 hours forecast. Whereas Polar WRF shows underestimation of 1.4 knots and 1.3 knots at 24 hours and 48 hours forecast. For GFS, RMSE ranges between 10.6 and 8 knots and for the Polar WRF, the values are 5.6 and 4.8 knots. The correlation coefficients of the forecasts against the observed values are 0.46 and 0.56 for the GFS forecasts. These values are 0.7 and 0.67 for the Polar WRF forecasts. Superiority of the Polar WRF over the GFS for $10 \mathrm{~m}$ height wind forecasts is clearly evident form these results.

AMPS is run at $45 \mathrm{~km}$ horizontal resolution and South Pole is kept at the centre of the model domain. The AMPS graphic outputs are available in the UCAR website http://www.mmm.ucar.edu/rt/amps/. Similar results for AMPS (as in tables 2 and 3 ) could not be included in this study due to nonaccessibility of digital outputs of AMPS. However, graphic products pf AMPS are used in the following section to compare the forecast flow patterns with that of Polar WRF.

\subsection{Validation of forecast flow pattern}

The 'Maitri' station is located at lat. $70^{\circ} 45^{\prime} \mathrm{S}$, long. $11^{\circ} 44^{\prime} \mathrm{E}$ and the model domain is centered at 'Maitri' with $400 \times 400$ grid points. Between the $60^{\circ}$ and $65^{\circ} \mathrm{S}$ latitudes there exists the Antarctic
Circumpolar Trough, a zone of low pressure that contains variable winds flowing from west to east. The importance of this region is that the fierce storms sweep warm moist air from the middle latitudes towards the pole, causing clouds and precipitation. Storms usually last for a few days, before a brief clearing, then another storm system. In order to illustrate the performance of Polar WRF, case studies of two weather events are illustrated in this paper.

\subsubsection{Low pressure system of 8-9 March 2011}

On 8 March 2011, a low pressure area lay around north of Maitri region. Forecast parameters considered for this exercise are: (a) mean sea level pressure and (b) surface (10 $\mathrm{m}$ height) wind-superimposed $2 \mathrm{~m}$ height temperature. For comparison purpose, corresponding analysis and forecast fields of AMPS are used.

Figure 4 displays analysis of mean sea level pressure field and surface (10 $\mathrm{m}$ height) windsuperimposed $2 \mathrm{~m}$ height temperature based on Polar WRF and the corresponding AMPS products valid at 0000 UTC of 8 March 2011. For the AMPS, the model domain is centred at the Pole, whereas for the Polar WRF centre of the model centre is at Maitri. The horizontal resolution of AMPS is $45 \mathrm{~km}$ and the model domain is also different from that of Polar WRF.

In the Polar WRF analysis, two low pressure areas are seen to the northwest of Maitri. Two circulations in the $10 \mathrm{~m}$ height wind field as located over this area also justifies the presence of two low pressure areas. The distribution of $2 \mathrm{~m}$ height temperature shows $-10^{\circ} \mathrm{C}$ over Maitri which increases to the north and becomes $10^{\circ} \mathrm{C}$ over the area of low pressure areas. These features, like two low pressure areas to the north-west of Maitri and increase of $2 \mathrm{~m}$ height temperature from $-10^{\circ} \mathrm{C}$ over Maitri

Table 3. 24 hours and 48 hours forecast skill scores of $10 \mathrm{~m}$ height wind speed of Maitri for the period from 1 December 2010 to 28 February 2011.

\begin{tabular}{|c|c|c|c|c|}
\hline & Wind (kt) & $\begin{array}{c}\text { Mean } \\
\text { errors (kt) }\end{array}$ & $\begin{array}{c}\text { Root mean } \\
\text { square } \\
\text { errors (kt) }\end{array}$ & $\begin{array}{c}\text { Correlation } \\
\text { coefficient }\end{array}$ \\
\hline \multicolumn{5}{|l|}{24 hours } \\
\hline Observation & 14.3 & & & \\
\hline GFS & 16.1 & 1.9 & 10.6 & 0.46 \\
\hline PWRF & 12.8 & -1.4 & 5.6 & 0.70 \\
\hline \multicolumn{5}{|l|}{48 hours } \\
\hline Observation & 14.3 & & & \\
\hline GFS & 10.5 & -3.8 & 8.0 & 0.56 \\
\hline PWRF & 13.0 & -1.3 & 4.8 & 0.67 \\
\hline
\end{tabular}




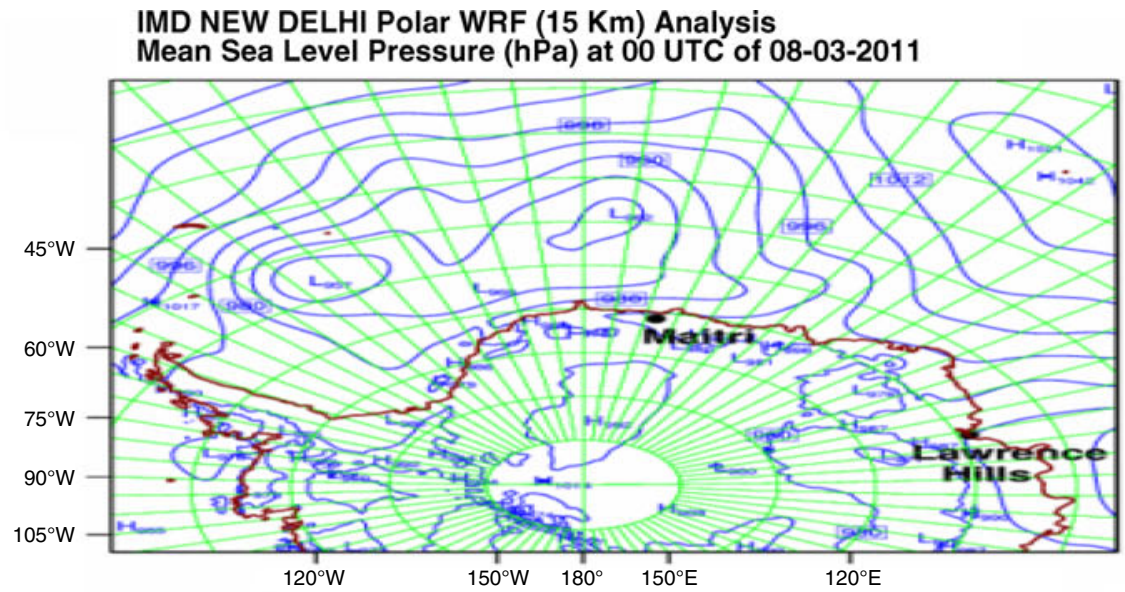

IMD NEW DELHI Polar WRF (15 Km) Analysis

$10 \mathrm{~m}$ Wind(Kts) \& $2 \mathrm{~m}$ Temp. $\left({ }^{\circ} \mathrm{C}\right)$ at $00 \mathrm{UTC}$ of $08-03-2011$
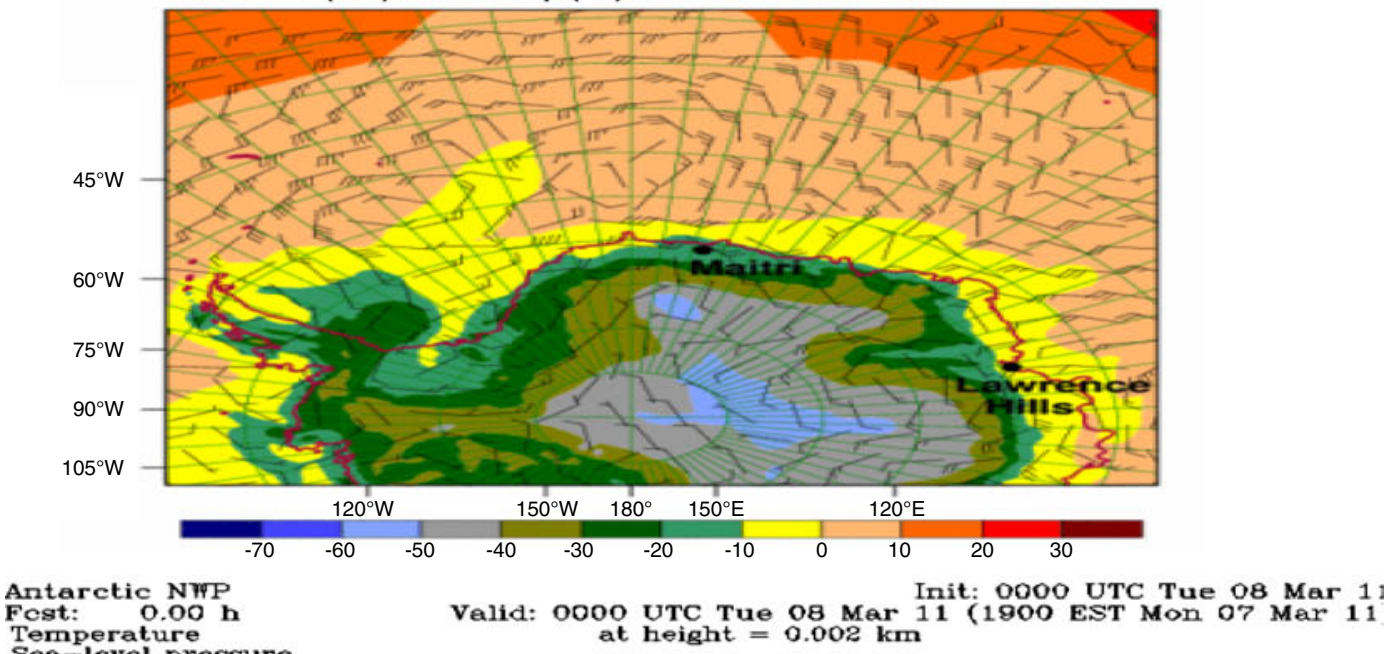

Temperature

$\begin{array}{ll}\text { Sea-level pressure } & \text { at height }=0.010 \mathrm{~cm}\end{array}$

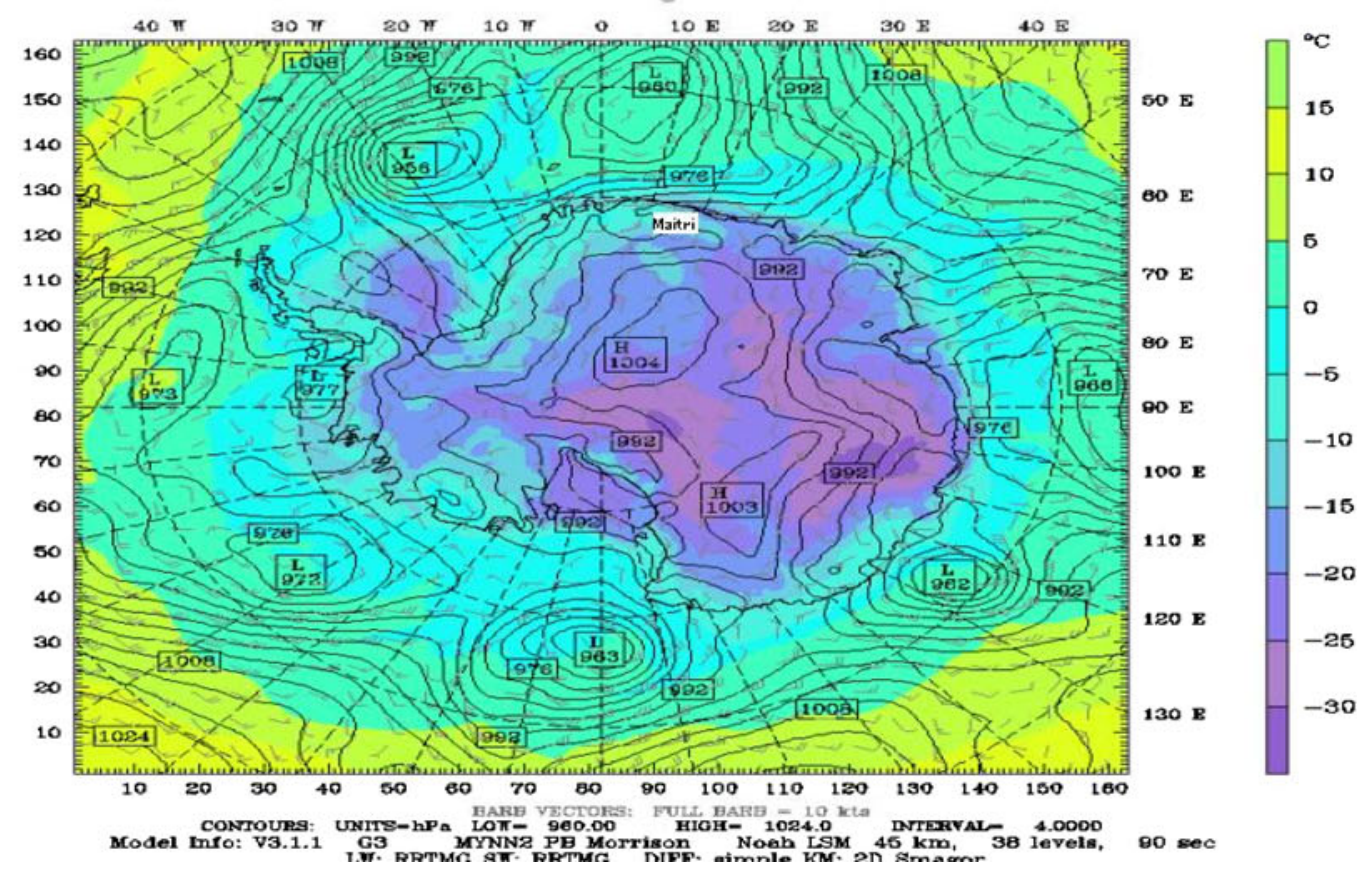

Figure 4. Analysis field valid at 0000 UTC of 8 March 2011 for (a) mean sea level pressure (hPa), (b) $10 \mathrm{~m} \mathrm{height} \mathrm{winds}$ (knot) and $2 \mathrm{~m}$ height temperature $\left({ }^{\circ} \mathrm{C}\right.$ ) based on Polar $\mathrm{WRF}$, and (c) mean sea level pressure and $2 \mathrm{~m}$ height temperature based on AMPS. 
IMD NEW DELHI Polar WRF (15Km) FORECAST (24 hr)

Mean Sea Level Pressure (hPa) based on 00 UTC of 08-03-2011 valid for 00 UTC of 09-03-2011

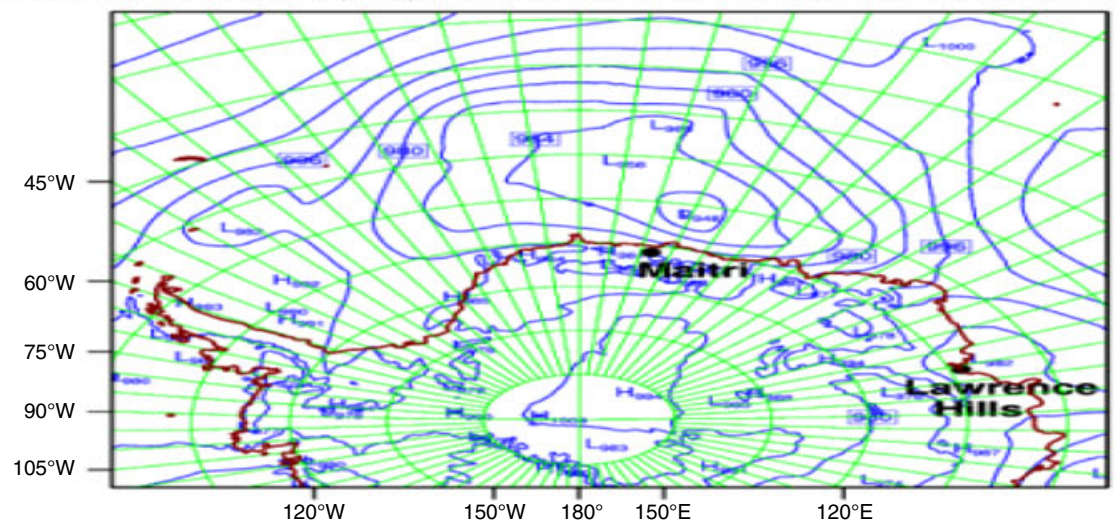

IMD NEW DELHI Polar WRF (15Km) FORECAST (24 hr)

$10 \mathrm{~m}$ Wind(Kts) \& $2 \mathrm{~m} \mathrm{Temp},\left({ }^{\circ} \mathrm{C}\right)$ based on 00 UTC of 08-03-2011 valid for 00 UTC of 09-03-2011
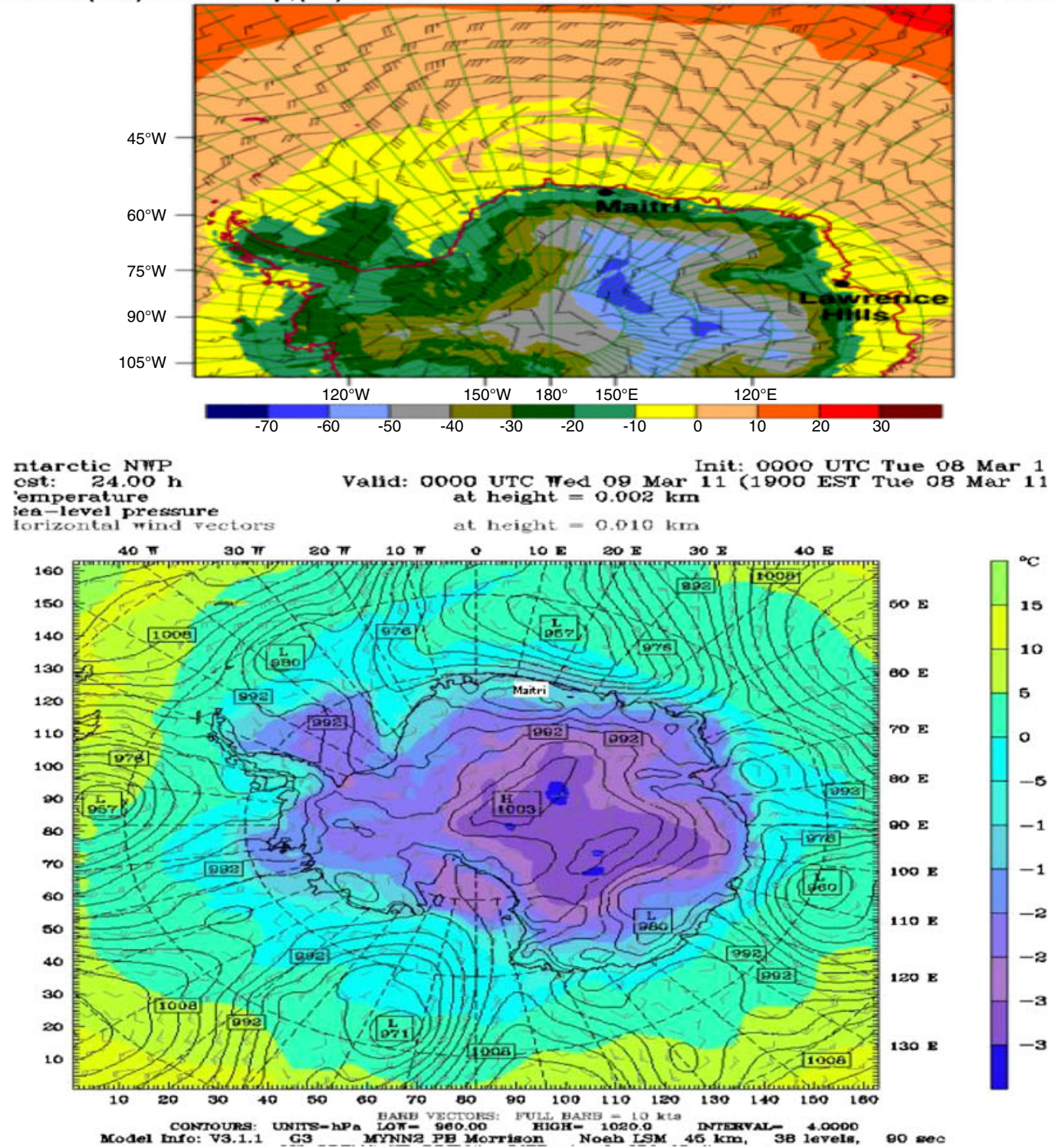

Figure 5. 24 hours forecast field valid at 0000 UTC of 9 March 2011 for (a) mean sea level pressure (hPa), (b) $10 \mathrm{~m}$ height winds (knot) and $2 \mathrm{~m}$ height temperature $\left({ }^{\circ} \mathrm{C}\right)$ based on Polar WRF, and (c) mean sea level pressure and $2 \mathrm{~m}$ height temperature based on AMPS. 
IMD NEW DELHI POlar WRF $(15 \mathrm{~km}$ ) FORECAST (48 $\mathrm{hr}$ )

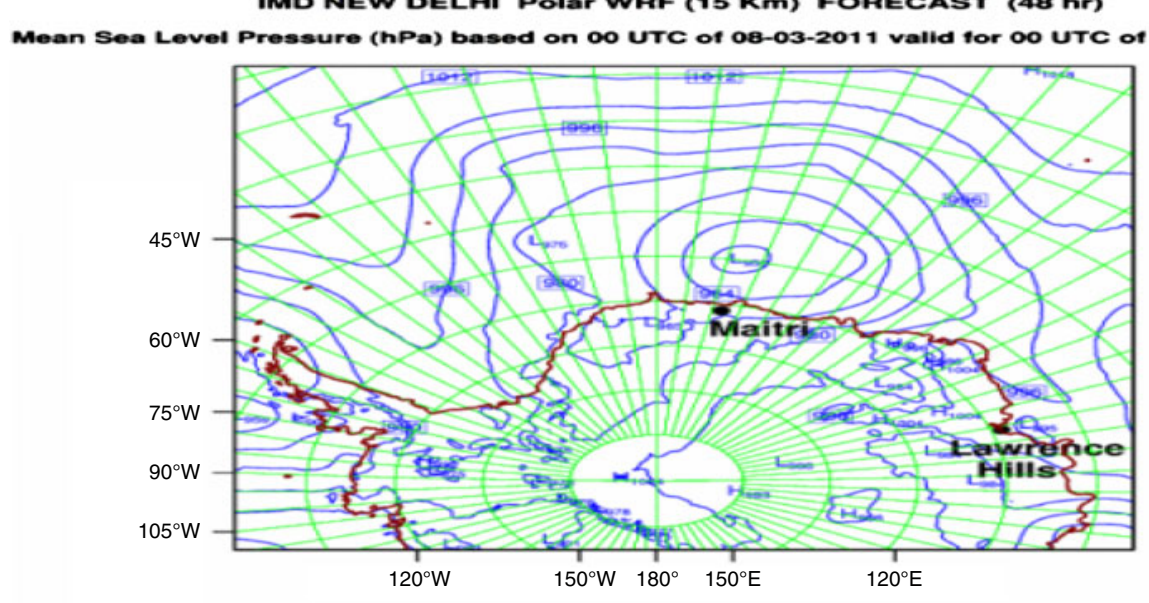

IMD NEW DELHI POlar WRF $(15 \mathrm{~km}$ ) FORECAST (48 $\mathrm{hr}$ )

$10 \mathrm{~m}$ Wind(kts) a $2 \mathrm{~m}$ Temp.( ${ }^{\circ} \mathrm{C}$ ) based on 00 uTC of ob-03-2011 valld for 00 urC of 10-03-2011
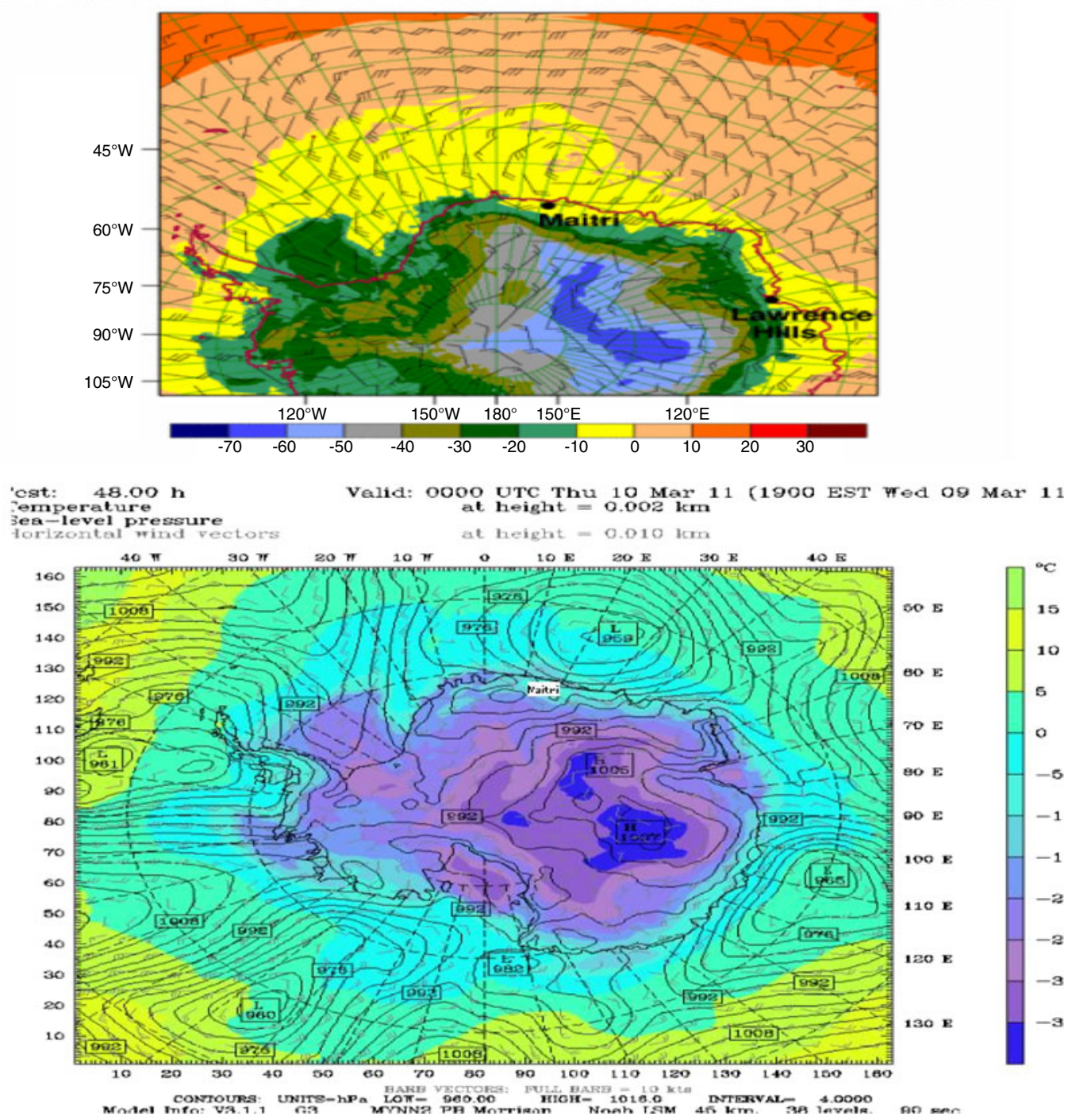

Figure 6. 48 hours forecast field valid at 0000 UTC of 10 March 2011 for (a) mean sea level pressure (hPa), (b) $10 \mathrm{~m}$ height winds (knot) and $2 \mathrm{~m}$ height temperature $\left({ }^{\circ} \mathrm{C}\right)$ based on Polar WRF, and $(\mathbf{c})$ mean sea level pressure and $2 \mathrm{~m}$ height temperature based on AMPS. 
IMD NEW DELHI Polar WRF (15 Km) Analysis

Mean Sea Level Pressure (hPa) at 00 UTC of 11-07-2011

(a)

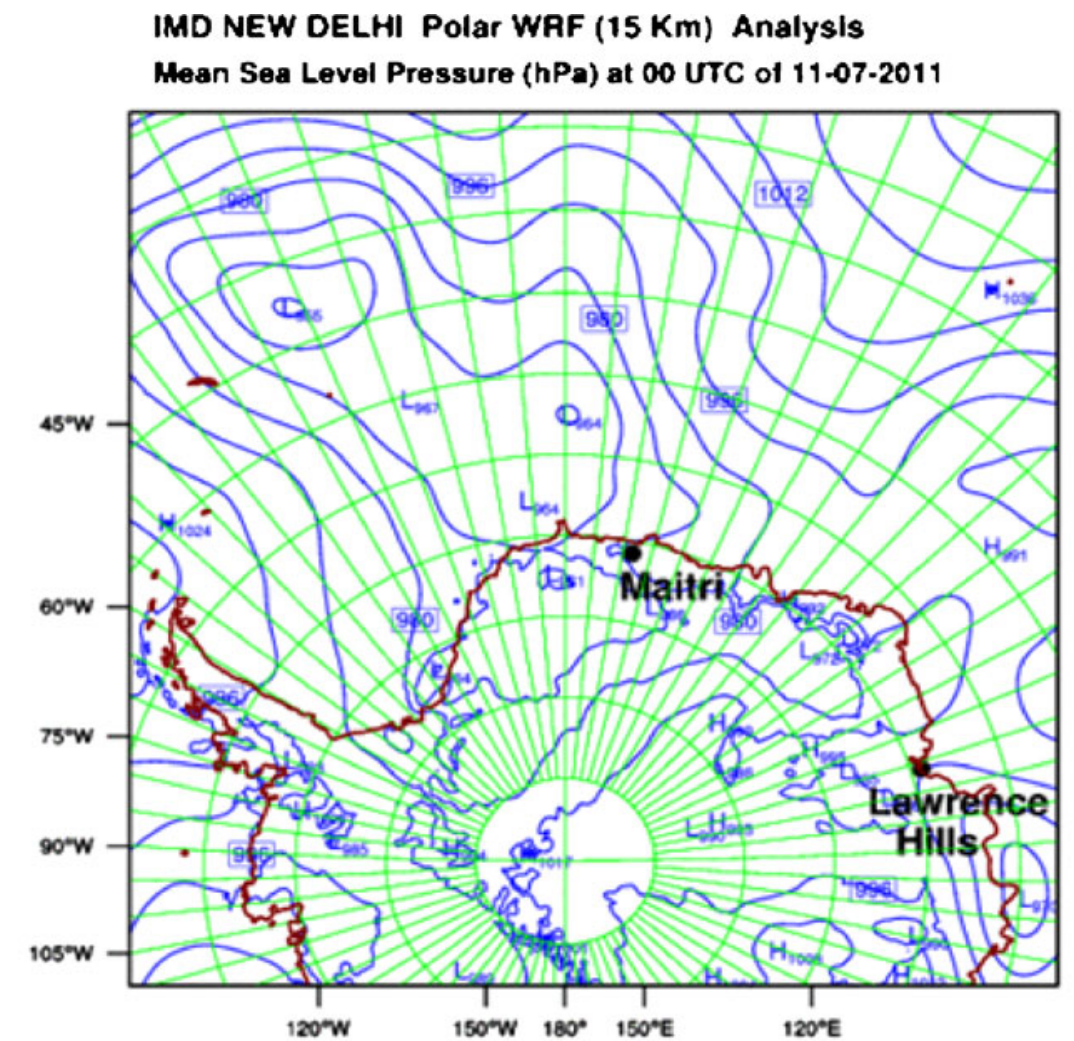

IMD NEW DELHI Polar WRF (15 Km) FORECAST (24 hr) Mean Sea Level Pressure (hPa) based on 00 UTC of 11-07-2011 valid for 00 UTC of 12-07-2011

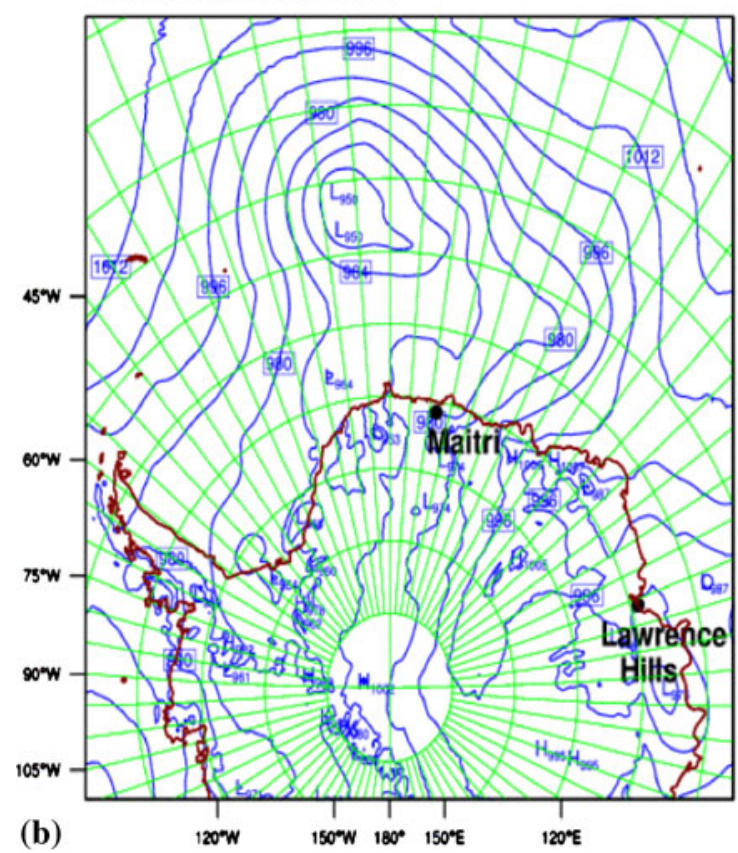

IMD NEW DELHI Polar WRF (15 Km) FORECAST ( $48 \mathrm{hr}$ ) Mean Sea Level Pressure (hPa) based on 00 UTC of 11-07-2011 valid for 00 UTC of 13-07-2011

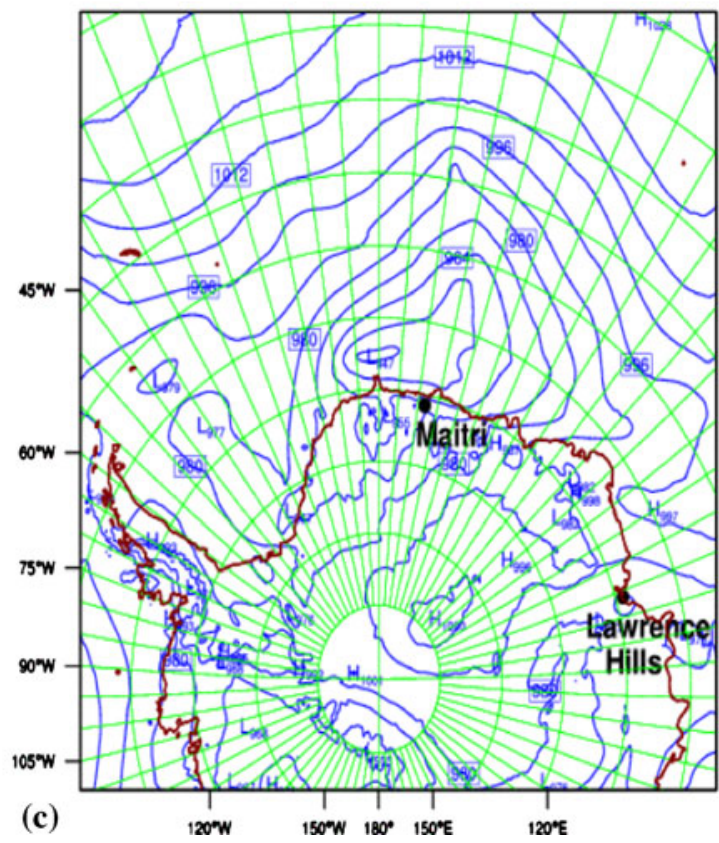

Figure 7. (a) Analysis field of mean sea level pressure (hPa) valid at 0000 UTC of 11 July 2011, (b) 24 hours forecast field of mean sea level pressure (hPa) valid at 0000 UTC of 12 July 2011 , (c) 48 hours forecast field of mean sea level pressure (hPa) valid at 0000 UTC of 13 July 2011, (d) 24 hours forecast field of snow (mm) valid at 0000 UTC of 12 July 2011, and (e) 48 hours forecast field of snow (mm) valid at 0000 UTC of 13 July 2011. 

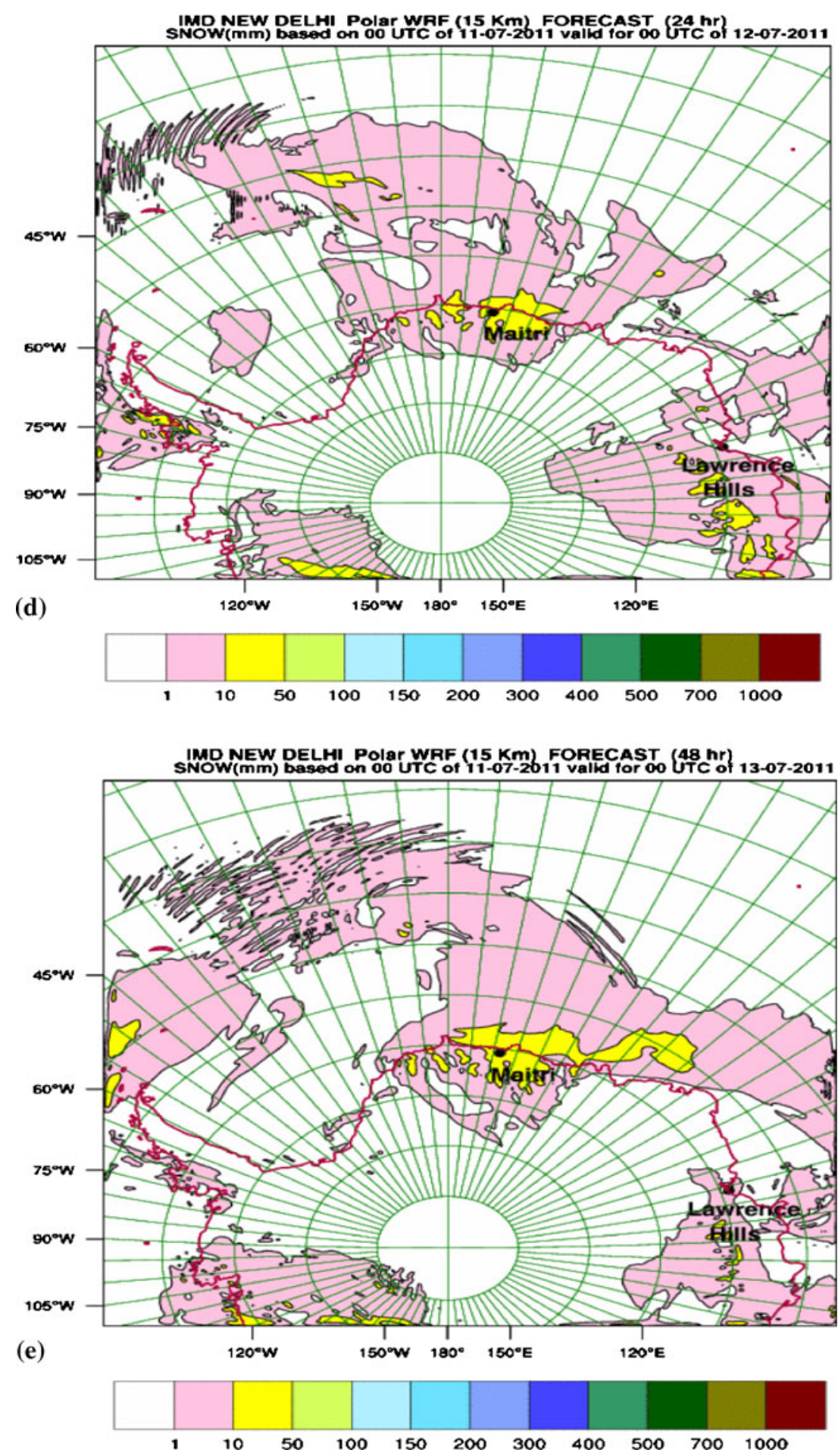

Figure 7. (Continued)

region to the areas of low pressure are also reflected in the AMPS analysis field.

Figure 5 shows 24 hours forecast of mean sea level pressure field and surface (10 m height) windsuperimposed $2 \mathrm{~m}$ height temperature based on Polar WRF and the corresponding AMPS products valid at 0000 UTC of 9 March 2011. In the forecast, two low pressure areas merged into a single low pressure area and lay north of Maitri, which is also reflected in the $10 \mathrm{~m}$ height wind field. The features are found to be consistent with the corresponding APMS forecast charts. 
IMD NEW DELHI Polar WRF (15 Km) Analysis

Mean Sea Level Pressure (hPa) at 00 UTC of 12-07-2011

(a)

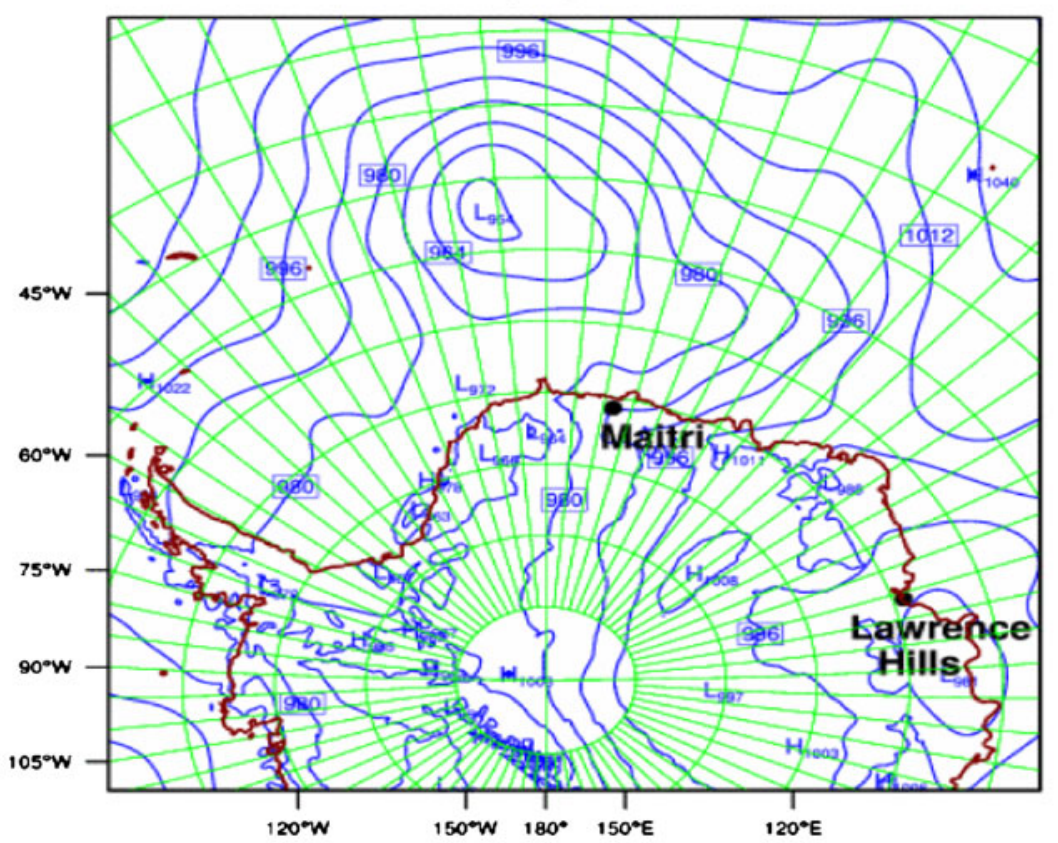

IMD NEW DELHI Polar WRF (15 Km) FORECAST (24 hr) Mean Sea Level Pressure (hPa) based on 00 UTC of 12-07.2011 valid for 00 UTC of 13-07-2011

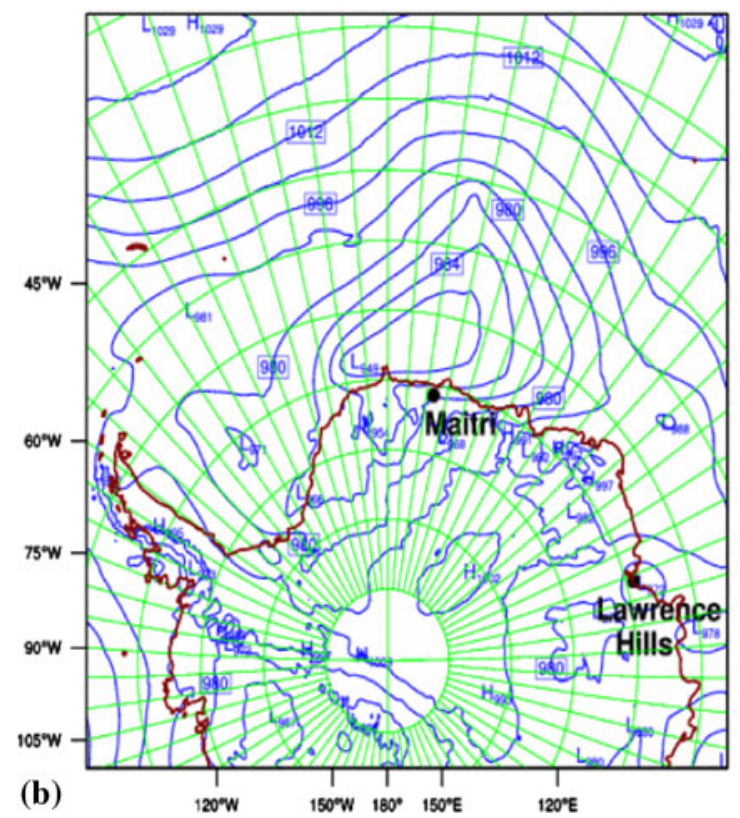

IMD NEW DELHI Polar WRF (15 Km) FORECAST ( $48 \mathrm{hr}$ ) Mean Sea Level Pressure ( $\mathrm{hPa}$ ) based on 00 UTC of 12-07-2011 valid for 00 UTC of 14-07-2011

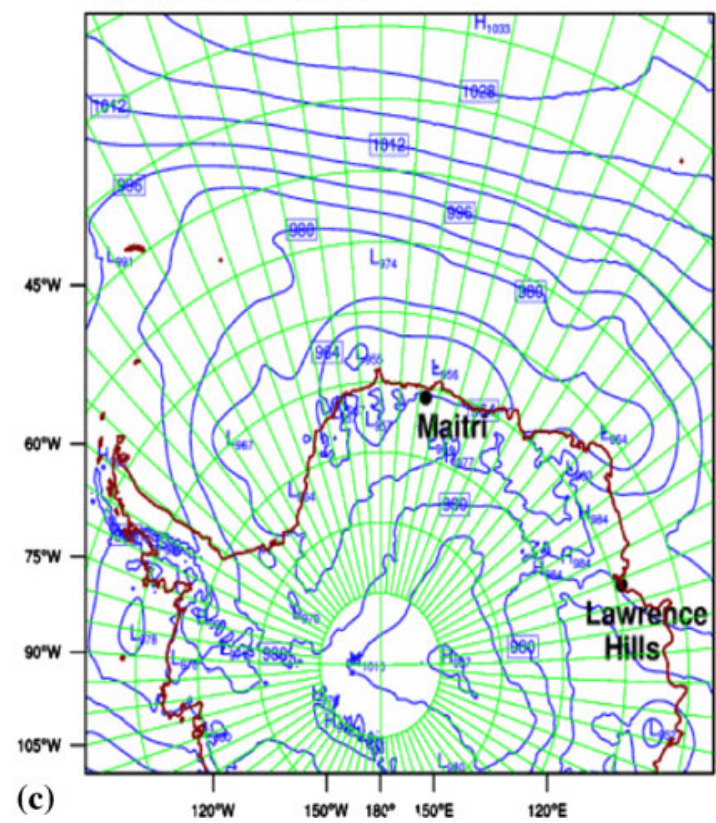

Figure 8. (a) Analysis field of mean sea level pressure (hPa) valid at 0000 UTC of 12 July 2011, (b) 24 hours forecast field of mean sea level pressure (hPa) valid at 0000 UTC of 13 July 2011, (c) 48 hours forecast field of mean sea level pressure (hPa) valid at 0000 UTC of 14 July 2011, (d) 24 hours forecast field of snow (mm) valid at 0000 UTC of 13 July 2011 and (e) 48 hours forecast field of snow (mm) valid at 0000 UTC of 14 July 2011.

Figure 6 shows 48 hours forecast of mean sea level pressure field and surface (10 $\mathrm{m}$ height) windsuperimposed $2 \mathrm{~m}$ height temperature based on Polar WRF and the corresponding AMPS products valid at 0000 UTC of 9 March 2011. In the Polar
WRF, the low pressure system moved slightly eastwards and lay just north of Maitri. In the AMPS, the movement of the system to the east is found to be faster at the 48 hours forecast. Otherwise, both the forecasts are found to be consistent. 

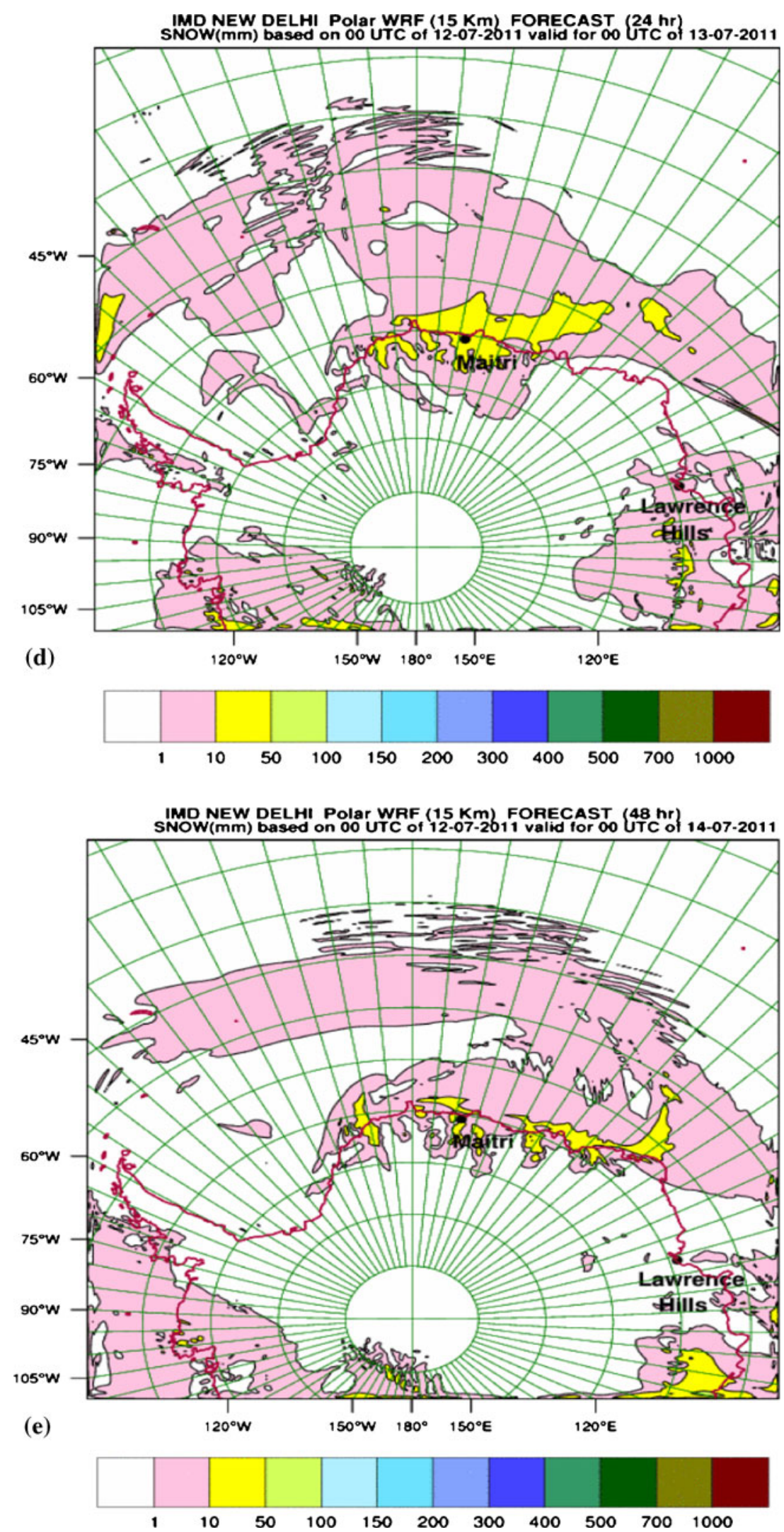

Figure 8. (Continued) 
IMD NEW DELHI Polar WRF (15 Km) Analysis

Mean Sea Level Pressure (hPa) at 00 UTC of 13-07-2011

(a)

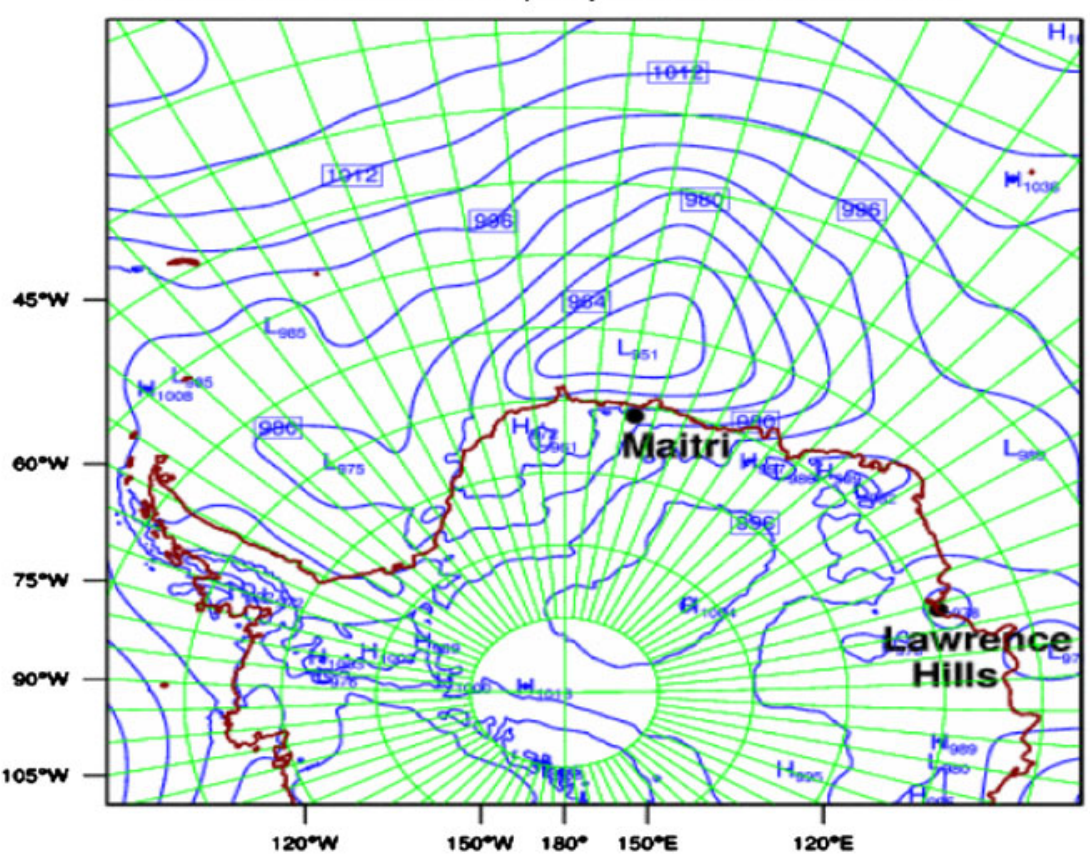

IMD NEW DELHI POlar WRF (15 Km) FORECAST (24 hr) Mean Sea Level Pressure ( $\mathrm{hPa}$ ) based on 00 UTC of 13-07-2011 valld for 00 UTC of 14-07-2011

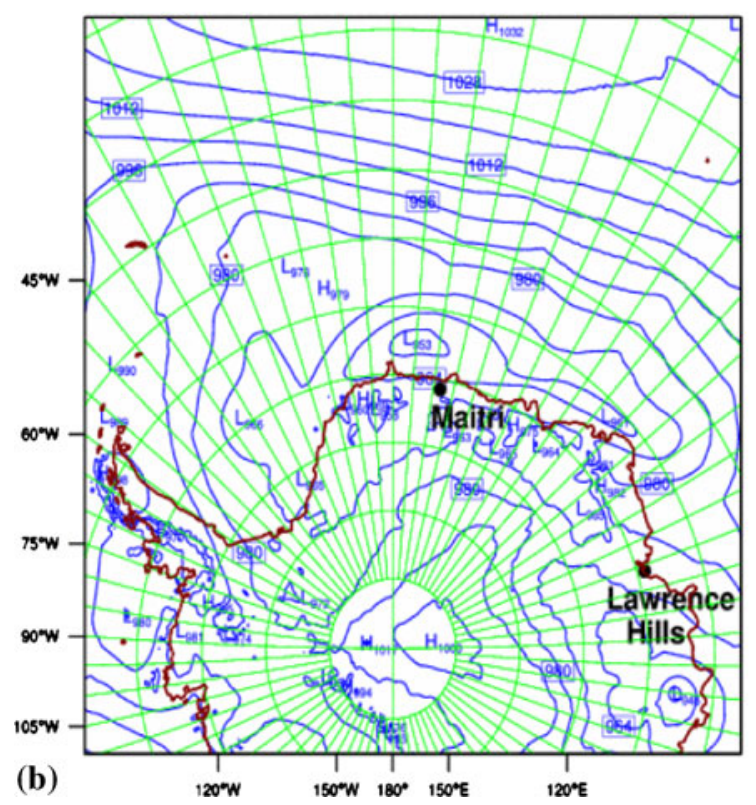

IMD NEW DELHI POlar WRF (15 Km) FORECAST (48 hr) Mean Sea Level Pressure (hPa) based on 00 UTC of 13-07-2011 valid for 00 UTC of 15-07-2011

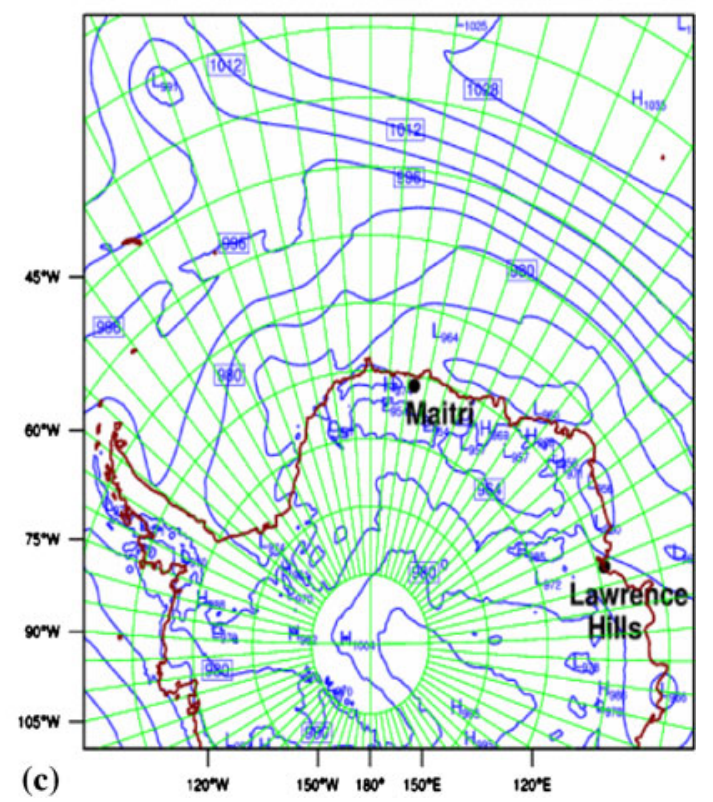

Figure 9. (a) Analysis field of mean sea level pressure (hPa) valid at 0000 UTC of 13 July 2011, (b) 24 hours forecast field of mean sea level pressure (hPa) valid at 0000 UTC of 14 July 2011, (c) 48 hours forecast field of mean sea level pressure (hPa) valid at 0000 UTC of 15 July 2011, (d) 24 hours forecast field of snow (mm) valid at 0000 UTC of 14 July 2011, and (e) 48 hours forecast field of snow (mm) valid at 0000 UTC of 15 July 2011.

\subsubsection{Low pressure system of 11-14 July 2011}

An event of intense blizzard activity was reported by IMD Maitri station on 13 July 2011 during the passage of an intense low pressure system. This case is selected to examine the performance of
Polar WRF to capture weather features associated with a blizzard activity. Analysis field of mean sea level pressure $(\mathrm{hPa})$ valid at $0000 \mathrm{UTC}$ of 11 July and the 24 hours and 48 hours forecast fields of mean sea level pressure $(\mathrm{hPa})$ valid at $0000 \mathrm{UTC}$ of 12 and 13 July are shown in figure $7(\mathrm{a}, \mathrm{b}, \mathrm{c})$ 

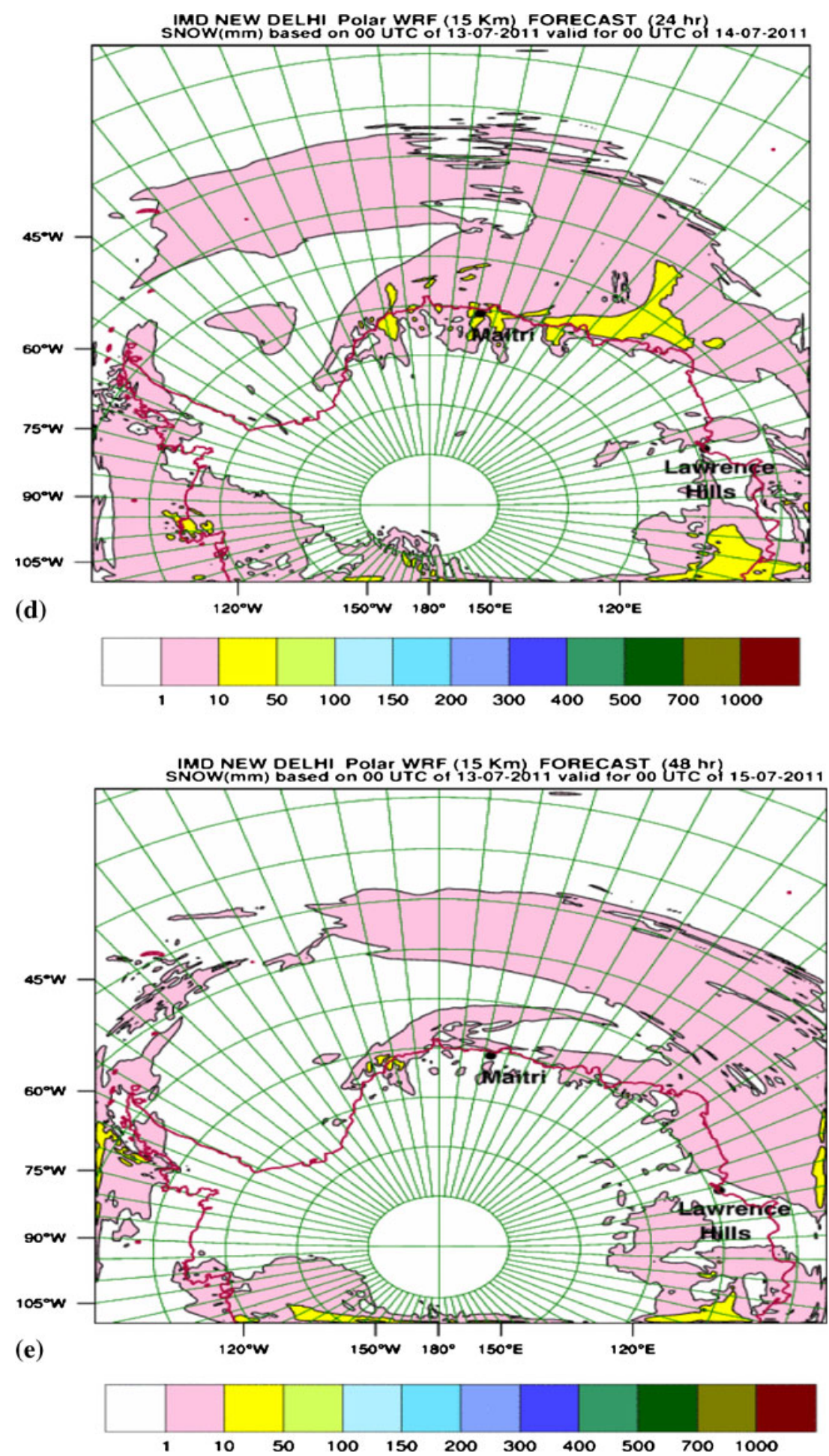

Figure 9. (Continued)

respectively. Corresponding forecast snowfall distribution $(\mathrm{mm})$ are shown in figure $7(\mathrm{e}, \mathrm{f})$ respectively. In the analysis, a low pressure system lay to the northwest of Maitri. The low pressure system became more organized and moved towards Maitri in the 24 hours forecast valid at 0000 UTC of 12 July. The system, in the 48 hours forecast valid at 0000 UTC of 13 July, moved further eastwards towards Maitri and lay with centre very close to Maitri. In the corresponding forecast field of snowfall distribution, maximum snowfall of amount $50 \mathrm{~mm}$ is noticed over Maitri region and neighbouring areas on 12 July in the 24 hours forecast. The maximum snowfall belt is found to 
IMD NEW DELHI Polar WRF (15 Km) Analysis

Mean Sea Level Pressure (hPa) at 00 UTC of 14-07-2011

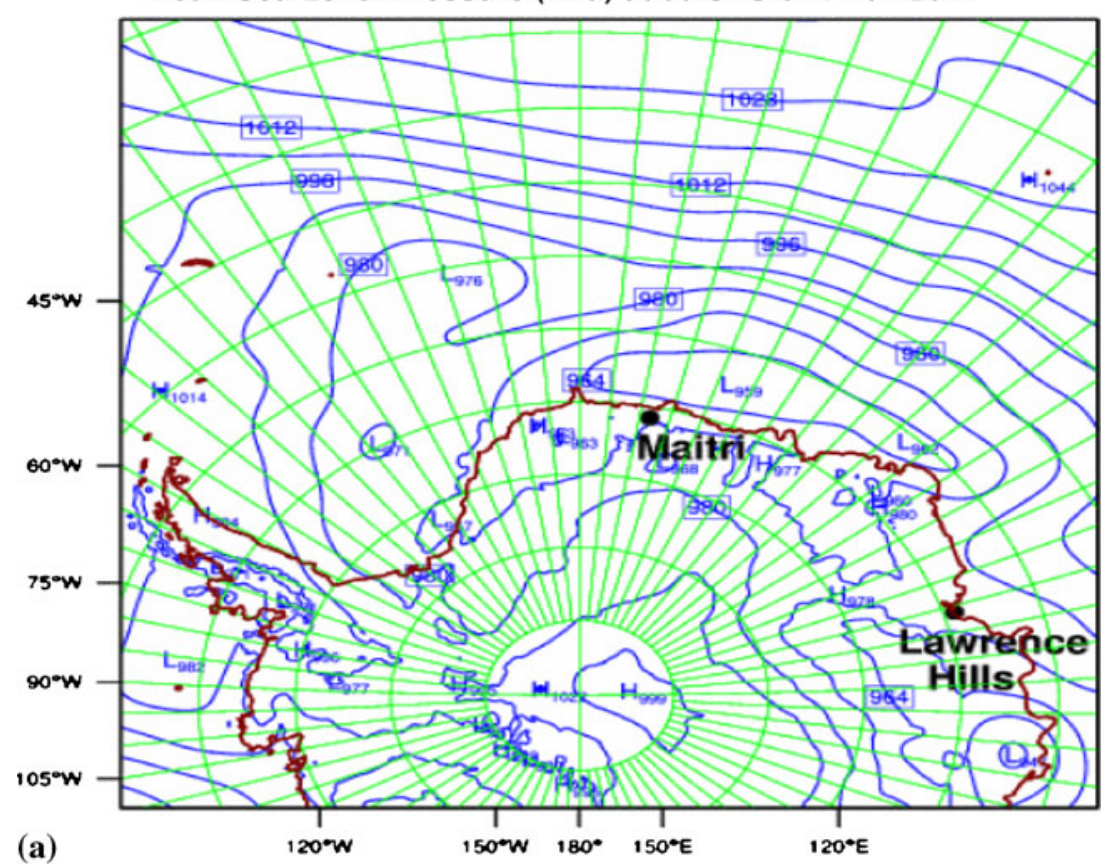

(a)

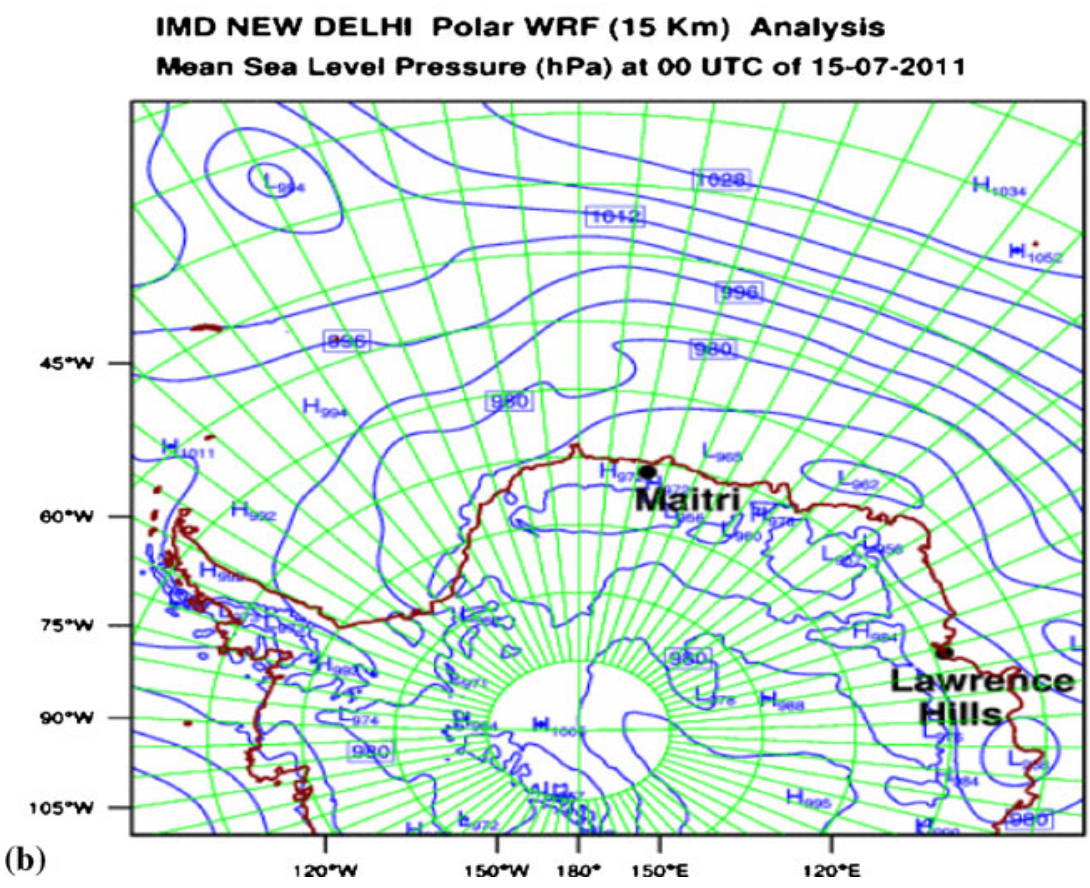

Figure 10. Analysis field of mean sea level pressure (hPa) valid at 0000 UTC of (a) 14 July 2011 and (b) 15 July 2011.

be extended to eastwards in the corresponding 48 hours forecast valid at 0000 UTC of 13 July.

Analysis and forecasts of mean sea level pressure generated based on 0000 UTC of 12 July are presented in figure $8(\mathrm{a}, \mathrm{b}, \mathrm{c})$. In the analysis of the mean sea level pressure, the well marked low pressure system is located northwest of Maitri. This is found to be well captured in the corresponding 24 hours forecast of 11 July (as shown in figure $7 \mathrm{~b}$ ). In the 24 hours forecast valid at 0000 UTC of 13 July, the intense low pressure system lay with centre close to Maitri. In the 48 hours forecast valid at 0000 UTC of 14 July, the low pressure system became considerably less marked and lay as an east-west oriented trough line, spreading over a large area. Corresponding 24 hours forecast field of 
snowfall (figure 8d) shows east-west oriented snowfall belt of intensity $50 \mathrm{~mm}$ around Maitri region. In the corresponding 48 hours forecast (figure 8e), the intensity of the snowfall around Maitri region is found to be less intense.

Analysis and forecasts of mean sea level pressure generated based on 0000 UTC of 13 July are presented in figure $9(\mathrm{a}, \mathrm{b}, \mathrm{c})$. In the analysis of the mean sea level pressure, the organized low pressure system is located with centre very close Maitri. This is found to be well captured in the corresponding 48 hours forecast of 11 July (as shown in figure 7c) and 24 hours forecast of 12 July (as shown in figure $8 \mathrm{~b}$ ). In the 24 hours forecast valid at 0000 UTC of 14 July, the intense low pressure system became considerably less marked and lay as an east-west oriented trough line, spreading over a large area. This is found to be consistent with the corresponding 48 hours forecast of 12 July (as shown in figure $8 \mathrm{c}$ ). Corresponding 24 hours forecast field of snowfall (figure 9d) valid at 0000 UTC of 14 July, shows east-west oriented snowfall belt of intensity $50 \mathrm{~mm}$ around Maitri region. In the corresponding 48 hours forecast (figure 9e) valid at 0000 UTC of 15 July, the intensity of the snowfall around Maitri region is found to be less intense. In figure 10(a, b), analysis field of mean sea level pressure fields (hPa) valid at 0000 UTC of 14 July 2011 and 15 July 2011 respectively are presented. The weakening of the low pressure as reflected in these figures, is clearly captured in the corresponding forecasts generated on 12 and 13 July.

Figure 11 presents Meteogram of Maitri for 48 hours forecast issued at 0000 UTC of 13 July 2011. Strong westerly winds of order around 100 knots are noticed in the hourly forecasts during morning 0000 UTC of 13 July to 0000 UTC of 14 July. Wind speed in the forecast started decreasing after 0000 UTC of 14 July and became 40 knots at 1200 UTC of 14 July. According to the observations received from Maitri station, wind speed has been 69 knots, gusting to 96 knots during 13 July. Thus, the model is able to provide realistic wind forecasts of this blizzard event. In the forecast, snowfall is observed

Maitri(Lat. $70^{\circ} 45^{\prime}$ S Lon. $11^{\circ} 44$ E) METEOGRAM 00Z13-07-2011
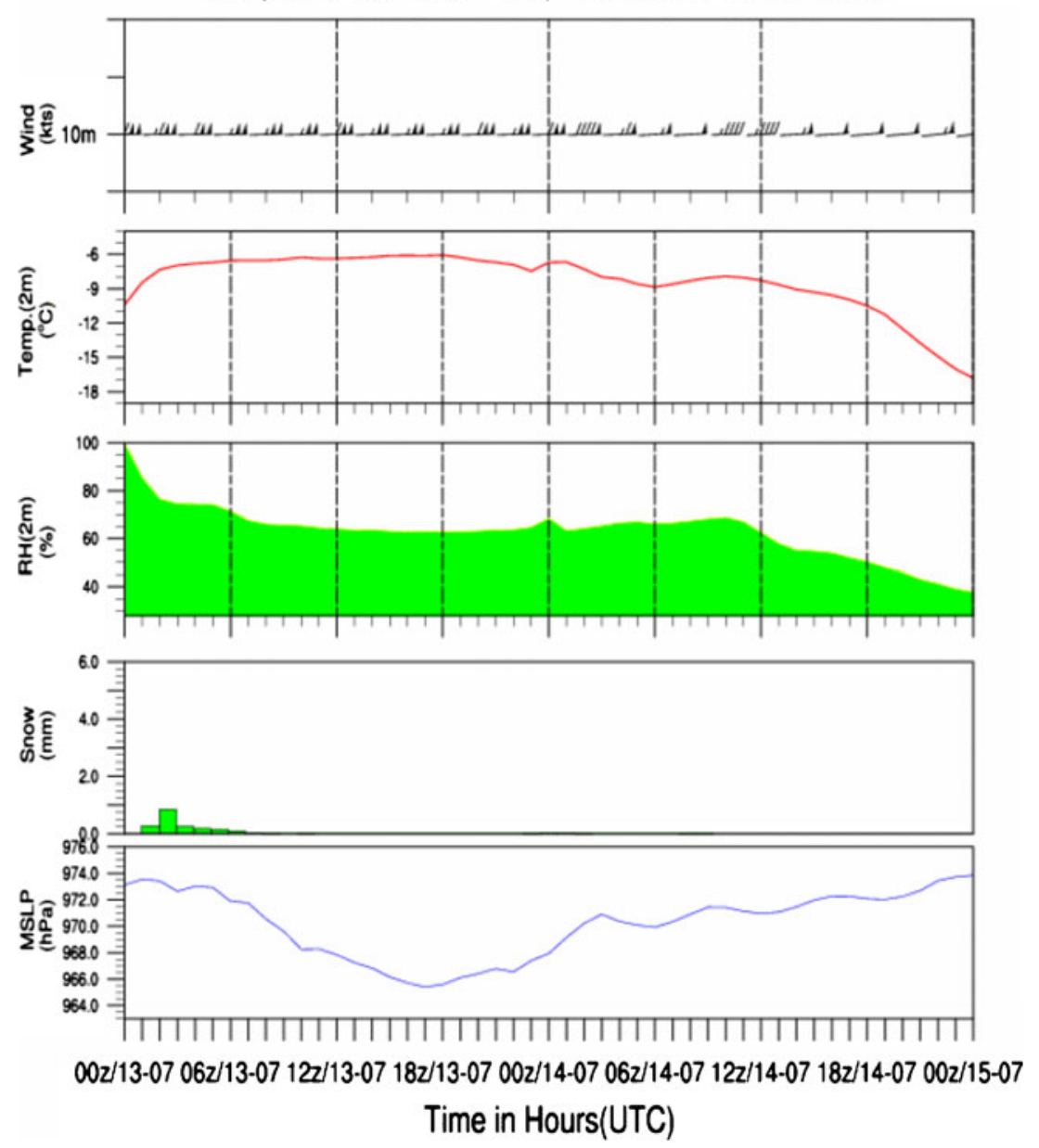

Figure 11. Meteogram of Maitri for 48 hours forecast issued at 0000 UTC of 13 July 2011. 
during early forecast hours up to 0800 UTC. Surface humidity in the forecast has been around $80 \%$ during 0000 UTC 13 July to 1200 UTC of 14 July and then started decreasing. It became $40 \%$ at 0000 UTC of 15 July, in the 48 hours forecast. Surface temperature has been around $-8^{\circ} \mathrm{C}$ at $0000 \mathrm{UTC}$ of 13 July to 0000 UTC 14 July, and then started decreasing. It became $-15^{\circ} \mathrm{C}$ at 0000 UTC of 15 July, after the ceasing of the blizzard event on 14 July. Mean sea level pressure started decreasing from $972 \mathrm{hPa}$ at $0000 \mathrm{UTC}$ of 13 July and became $966 \mathrm{hPa}$ at $1800 \mathrm{UTC}$ of 13 July. Thereafter again it started increasing and became 972 at 0000 UTC of 15 July. These results are found to be well comparable with the reports received from the Maitri station.

\section{Conclusions}

To meet the operational need of weather forecasts for Maitri region, recently Polar WRF at $15 \mathrm{~km}$ horizontal resolution is made operational at IMD New Delhi using IMD GFS T-382 as the initial and boundary conditions (the current operational version of the model is GFS T574). Location specific short range forecasts generated interpolating Polar WRF outputs are compared with the corresponding observed fields of Maitri and forecast fields of IMD GFS using data for the period of 90 days starting from 1 December 2010 to 28 February 2011. The time series of observed and corresponding forecast fields shown in this comparison indicates a high level of agreement of Polar WRF with the observed field. The performance statistics, such as mean errors, root mean square errors and correlation coefficient of forecasts of mean sea level pressure and $10 \mathrm{~m}$ height wind computed against the corresponding observations of Maitri clearly demonstrated the superiority of Polar WRF forecasts over the IMD GFS forecasts. The case studies presented in this paper clearly demonstrated the potential of the model to capture frontal low pressure systems and associated weather features. The study demonstrates the usefulness of the forecast products for short range forecasting of weather over the Maitri region.

However, these results being preliminary, further investigation is needed for a variety of different weather conditions during winter and summer months for identifying shortcomings of the model and aspects of the model that require additional development work in the future.

\section{Acknowledgements}

Authors are grateful to the Director General of Meteorology, India Meteorological Department, New Delhi for his keen interest in this study and providing all facilities and support to complete the work. Authors thankfully acknowledge the Meteorology Group of the Byrd Polar Research Center at the Ohio State University for use of the Polar WRF in this work and technical guidance through e-mail interactions.

\section{References}

Bromwich D H, Cassano J J, Klein T, Hrinemann G, Hines K M, Steffen K and Box J E 2001 Meso-scale modeling of katabatic winds over Greenland with Polar MM5; Mon. Weather Rev. 129 2290-2309.

Cassano J J and Parish T R 2000 An analysis of the nonhydrostatic dynamics in numerically simulated Antarctic katabatic flows; J. Atmos. Sci. 57 891-898.

Cassano J J, Parish T R and King J C 2001a Evaluation of turbulent surface flux parameterizations for the stable surface layer over Halley, Antarctica; Mon. Weather Rev. $12926-46$.

Cassano J J, Box J E, Bromwich D H, Li L and Steffen K 2001b Evaluation of Polar MM5 simulations of Greenland's atmospheric circulation; J. Geophys. Res. $10633,867-33,890$.

Hines K M and Bromwich D H 2008 Development and testing of Polar WRF. Part I. Greenland ice sheet meteorology; Mon. Weather Rev. 136 1971-1989.

Pandey P C 2007 "India: Antarctic Program", Encyclopedia of the Antarctic (ed.) Beau Riffenburgh, Abingdon and New York: Taylor \& Francis, ISBN 0-415-97024-5, pp. 529-530.

Parish T R and Cassano J J 2003 Diagnosis of the katabatic wind influence on the wintertime Antarctic surface wind field from numerical simulations; Mon. Weather Rev. 131 1128-1139.

Pavolonis M J, Key J R and Cassano J J 2004 A study of the Antarctic surface energy budget using a polar regional atmospheric model forced with satellite derived cloud properties; Mon. Weather Rev. 132 654-661.

Powers J G 2007 Numerical prediction of an Antarctic severe wind event with the weather research and forecasting (WRF) model; Mon. Weather Rev. 135 3134-3157.

Powers J G, Monaghan A J, Cayette A M, Bromwich D H, Kuo Y-H and Manning K W 2003 Real time mesoscale modeling over Antarctica: The Antarctica Meso-scale Prediction System (AMPS); Bull. Am. Meteor. Soc. 84 1533-1545.

Roy Bhowmik S K and Durai V R 2010 "Performance of Global Forecast System of IMD in the medium range time scale during summer monsoon 2010" - Monsoon 2010, A report of IMD, Met Mongraph Synoptic Meteorology No. 10/2011, pp. 101-132.

Schwedtfeger W 1984 Weather and Climate of Antartic; Elsevier, 261p. 